\title{
High Strain-Rate Constitutive Behavior of SAC105 and SAC305 Leadfree Solder During Operation at High Temperature
}

\author{
Pradeep Lall ${ }^{(1)}$, Di Zhang ${ }^{(1)}$, Vikas Yadav ${ }^{(1)}$, David Locker ${ }^{(2)}$ \\ (1) Auburn University \\ NSF-CAVE3 Electronics Research Center \\ Department of Mechanical Engineering \\ Auburn, AL, USA \\ (2) US Army AMRDEC, Huntsville, AL \\ Tele: (334)844-3424 \\ E-mail:1all@auburn.edu
}

\begin{abstract}
Industry migration to leadfree solders has resulted in a proliferation of a wide variety of solder alloy compositions. The most popular amongst these are the $\mathrm{Sn}-\mathrm{Ag}-\mathrm{Cu}$ family of alloys like SAC105 and SAC305. Electronics subjected to shock and vibration may experience strain rates of 1-100 per sec. Electronic product may often be exposed to high temperature during storage, operation and handling in addition to high strain rate transient dynamic loads during drop-impact, shock and vibration. Properties of leadfree solder alloys at high strain rates at low and high temperatures experienced by the solder joint during typical mechanical shock events are scarce. Previous studies have showed the effect of high strain rates and thermal aging on the mechanical properties of leadfree alloys including elastic modulus and the ultimate tensile strength. The ANAND viscoplastic constitutive model has been widely used to describe the inelastic deformation behavior of solders in electronic components. In this study, SAC105 and SAC305 leadfree alloys have been tested at strain rates of $10,35,50$ and 75 per sec at various operating temperatures of $50^{\circ} \mathrm{C}, 75^{\circ} \mathrm{C}$, $100^{\circ} \mathrm{C}$ and $125^{\circ} \mathrm{C}$. Full-field strain in the specimen have been measured using high speed imaging at frame rates up to $75,000 \mathrm{fps}$ in combination with digital image correlation. The cross-head velocity has been measured prior-to, during, and after deformation to ensure the constancy of cross-head velocity. Stress-Strain curves have been plotted over a wide range of strain rates and temperatures. Experimental data for the pristine specimen has been fit to the ANAND's viscoplastic model.
\end{abstract}

\section{Introduction}

Solder joint cracking is one of the predominant failure mechanisms in electronic products exposed to high Gloads in shock and vibration environments. Board assemblies are often subjected to a large amount of deformation in shock and vibration conditions resulting in accrued damage in the solder interconnects. Failure may occur in the first shock event or may result from cumulative damage from successive shock events. Therefore, a comprehensive understanding of solder alloy can play a great important role in electronic design and optimization. The constitutive properties of the solder joints are needed to capture the stress-strain behavior during transient deformation. Previously, Anand [1982] ${ }^{1}$,
Brown [1989 $]^{2}$ developed a set of viscoplastic constitutive equations for rate and temperature dependent materials. The Anand Viscoplasticity model was originally developed to describe hot-working (e.g. in excess of a homologous temperature of $0.5 \mathrm{~T}_{\mathrm{m}}$ ) of high strength aluminum and other structural metals and it has been extensively used to describe the viscoplastic deformation of $\mathrm{Sn}-\mathrm{Pb}$ and lead-free materials. Anand model has been implemented in several commercial finite element software including ANSYS ${ }^{\mathrm{TM}}$ and has been applied to describe mechanical behavior of solder alloys in low strain rate by a number of researchers. Leaded and Leadfree solder mechanical properties have been measured by previously, researchers with tension tests at low strain rates ( $\dot{\varepsilon}<1$ per sec) at different temperatures. The Anand Viscoplasticity model has been applied to both $\mathrm{SnPb}$ and lead-free materials. Darveaux $[1992]^{3}$ has developed constitutive relations for Tin-Based solder joints at range of strain rates between $10^{-8}$ and $10^{-1}$ per sec. Sung $[2002]^{4}$ represented the mechanical behavior of $\mathrm{Sn}-\mathrm{Pb}$ solder with a viscoplastic model by combining grain boundary sliding and matrix dislocation mechanism. Chen $[2006]^{5}$ presented a constitutive equation for $\mathrm{Sn}-\mathrm{Pb}$ solder including the kinematic hardening rule. Wang $[2007]^{6}$ has determined the Anand model constants for lead-free material (95.5Sn4.0Ag0.5Cu). Motalab [2012] used both stress-strain and creep data to determined Anand constants at low strain rates $(\dot{\varepsilon}=0.001,0.0001$, 0.00001 per sec). Pang $[1998]^{8}$ has shown that young's modulus and yield stress of $\mathrm{Sn}-\mathrm{Pb}$ are highly depended on strain rate and temperature. Pei [1995 $]^{9}$ executed tensile tests over a wide range of temperatures and low strain rates $\left(10^{-5}, 10^{-3}, 10^{-1}\right.$ per sec $)$ with two types of lead free materials $(96.5 \mathrm{Sn} 3.5 \mathrm{Ag}$ and $95.5 \mathrm{Sn} 3.8 \mathrm{Ag} 0.7 \mathrm{Cu})$. In addition the effects of room temperature aging on leadfree solder alloys properties have been evaluated by [Chuang 2002 $2^{10}$, Coyle 2000 ${ }^{11}$, Darveaux 2005 ${ }^{12}$, Lee $2002^{13}$, Pang $2004^{14}$, Tsui $2002^{15}$, Zhang $2009^{16}$ ] at low strain rate events $(<1$ per sec). Constitutive models for leadfree solders at high strain rates are scarce. Lall $\left[2010^{17}, 2011^{18}\right]$ has studied the mechanical properties of lead-free alloys, at different high strain rates $(\dot{\varepsilon}=10,35$, $50,75 \mathrm{sec}^{-1}$ ) and aging conditions, and shown the mechanical behaviors of solder joints are varied largely in different high strain rates conditions and aging days. High speed data acquiring system has been built to measure 
transient deformation of lead free materials at high strain rate. In the past, Digital Image Correlation (DIC) has been widely used to measure full field displacement and strain, when electronic products exposed to drop and shock events (Lall $\left[2008^{19}, 2009^{20}\right]$ ). In this study, the high strain rate properties of $\mathrm{Sn} 1 \mathrm{Ag} 0.5 \mathrm{Cu}$ (SAC105), $\mathrm{Sn} 3 \mathrm{Ag} 0.5 \mathrm{Cu}$ (SAC305) lead-free solder alloys at high temperatures have been measured. The measurement of the SAC105, SAC305 properties at high temperature is new. An impact hammer has been used in conjunction with digital image correlation and high-speed video for measurement of material constitutive behavior of leadfree SAC alloys in the strain rate range of 1-100 per sec has been captured. Anand constants have been estimated based on those stress-strain curves over different temperatures and strain rates. In addition, the accuracy of the extracted Anand constants has been evaluated by comparing the model prediction with experimental data.

\section{Sample Preparation}

Specimens which tested at high strain conditions were formed by using a vacuum suction process in high precision rectangular cross-section glass tubes, as shown in Figure 1. Firstly, cutting leadfree solder bar into pieces and then putting those into a quartz crucible. These solder specimens will be melted in this crucible by using a solder pot which maintained temperature around $240^{\circ} \mathrm{C}$. One end of the high precision rectangular glass tube insert into the melting solder alloy.

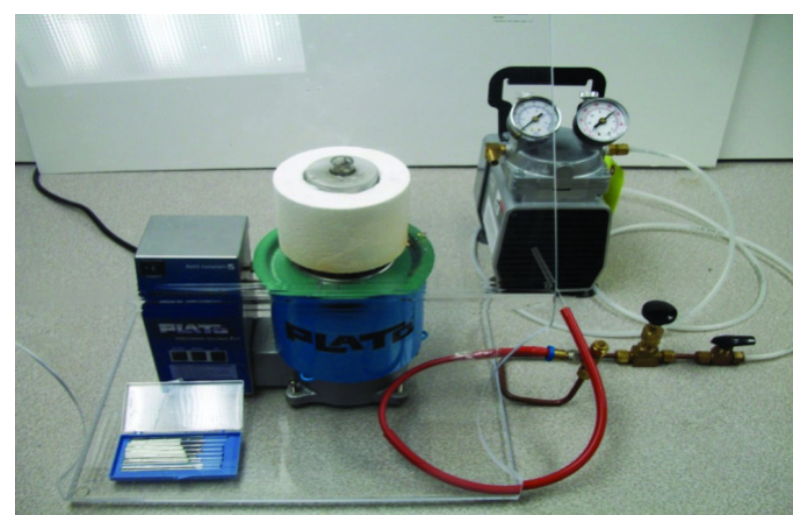

Figure 1: Specimen Preparation Setup

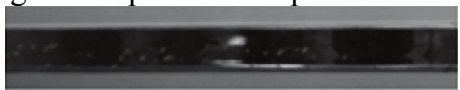

Figure 2: Specimen Inside Glass Tube

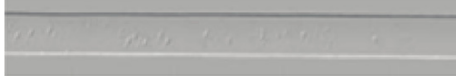

Figure 3: Specimen under X-ray inspection

The other end of the glass tube needs to be plugged into a rubber tube which has been connected to a vacuum pump. This pump provides consistent pressure to make sure the melted solder comes into glass tubes from crucible. In order to get a desired amount of solder rise into glass tubes, as shown in Figure 1, a regulator must be introduced to control suction forces on vacuum line. Then the glass tube has been removed from the heated crucible.
Water quenching method has been employed to decrease the temperature of specimens from high. After this, a reflow oven ( 9 zones Heller 1800EXL) has been applied to re-melt the solder strip through a user defined temperature profile. Thermocouples were attached to the glass tubes and monitored continuously using a radiofrequency KIC temperature profiling system to ensure that the samples are formed using desired temperature profile (same as commercial solder joints). Figure 4 shows the reflow temperature profile used for the reflow of the samples. The final solidified solder samples can be obtained by gently breaking the glass tube with vice after sample reflow and cool down. In the current study, uniaxial tensile test samples have been formed with nominal dimensions of $40 \times 5 \times 0.5 \mathrm{~mm}$. In order to match the typical BGA solder ball, a thickness of $0.5 \mathrm{~mm}$ has been chosen. Solder strips are tested by x-ray machine to make sure that all the specimens used in experimentation are away from void, indentation or premature crack in the gage length, as shown in Figure 2 and Figure 3.

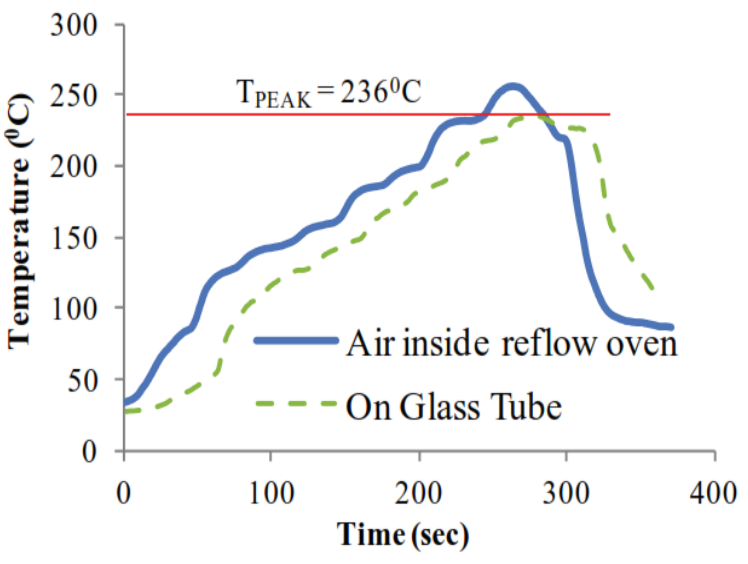

Figure 4: Reflow Profile

\section{Set-Up for Mechanical Testing}

In this experiment, different weight impact-hammers have been used to obtain different high strain rates test at high velocity. A slip joint has been employed to control crosshead, in order to attain a constant velocity prior to loading the specimen. An environmental chamber has been added to this testing system to control the inside conditions, which allows that samples can be tested over a wide temperature range of 25 to $300^{\circ} \mathrm{C}$, A thermal couple has been attached to this chamber to monitor the instantaneous temperature. The load frame of this testing system incorporates a piezoelectric load-cell and a linear voltage displacement transducer. The force data is recorded with high speed data acquired system running at 5 million samples per sec through load cell. In addition, high speed cameras operating at 75,000 fps have been used in conjunction with digital image correlation for the measurement of deformation during the test and the displacement and velocity of cross-head has been computed. In the entire tensile test, the heavy impact hammer and the slip joint ensure the cross-head to obtain 
a high speed and maintain a constant velocity respectively. A desired velocity has been achieved before any specimen deformation during the test by the elongation of slip joint. This stable velocity eliminates inertia effects during different dynamic loading conditions.

\section{Measurement of Cross-Head Strain Rate}

Two high speed cameras have been set up in front of the instrument to monitor the instantaneous movements of the slip joint and impact hammer, as shown in Figure 5

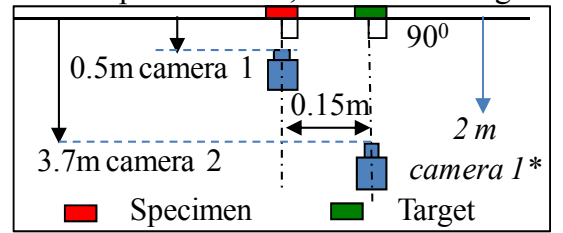

Figure 5: Camera Configuration for Capturing Specimen deformation at high strain-rate

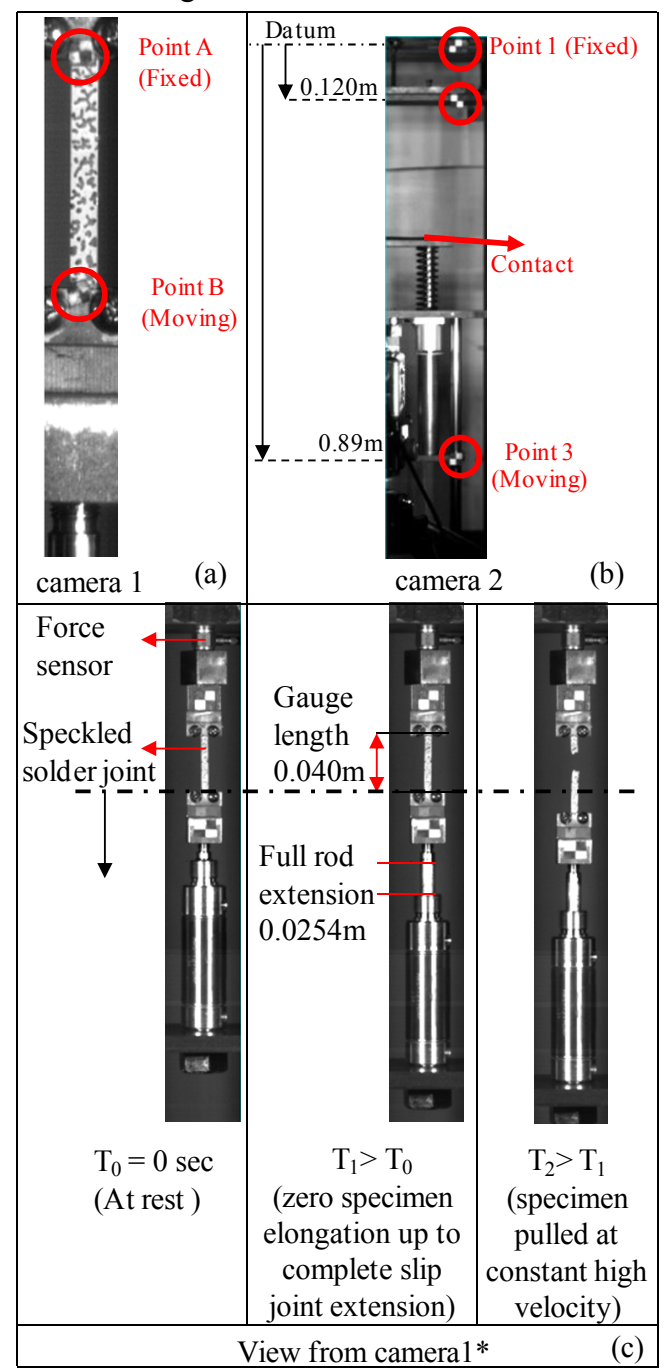

Figure 6: (a) High speed camera-1 monitoring cross-head motion. (b) High speed camera-2 monitoring targets. (c) Specimen configuration with a slip joint
View from camera 1, as shown in Figure 6(a). Two points, at the top and bottom of the specimen, have been monitored during running experimentation. Point $\mathrm{A}$ has been fixed at the frame and point $\mathrm{B}$ is moving along with cross head. View from camera 2, as shown in Figure 6(b). Three points have been used to monitor the complete tensile testing event. Point 1 is fixed to the frame and serves as a reference. Point 2 is attached to the impact hammer to follow the motion of free drop. Point 3 is attached to the bottom crosshead through the slip-joint. Moreover, all of these three targets have been mounted in a line and the same plane which is parallel to lens of camera 2 . In the test, point 2 is moving due to the free drop of the impact hammer. This movement consequently causes a metal contact, and then point 3 begins to move with the slip joint. After this slip joint finishing its elongation, point B, shown in Figure 6(a), begins to move with cross-head. Figure $7 \mathrm{a}$ top plot shows the relative motion of point B (bottom crosshead) with respect to point A (top cross head). Figure $7 \mathrm{~b}$ bottom plot shows the displacement as a function of time during specimen deformation. Figure 8(a) shows the relative motion of point 2 and point 3 with respect to point 1 for complete pull test event. Figure 8(b) in green circled region shows the time at when specimen starts elongating after when point 3 crosses $0.0254 \mathrm{~m}$ or 1 inch (rigid body motion) due to slip joint engagement.

(a)

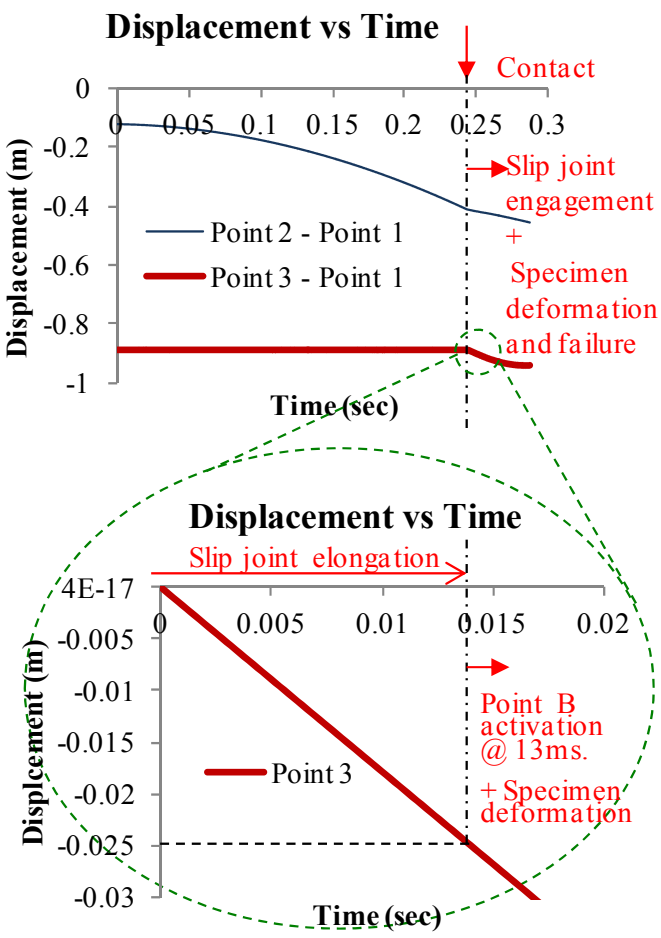

Figure 7: Dynamic input loading time-history (Using targets $(1,2$, and 3$))$ 
(a)

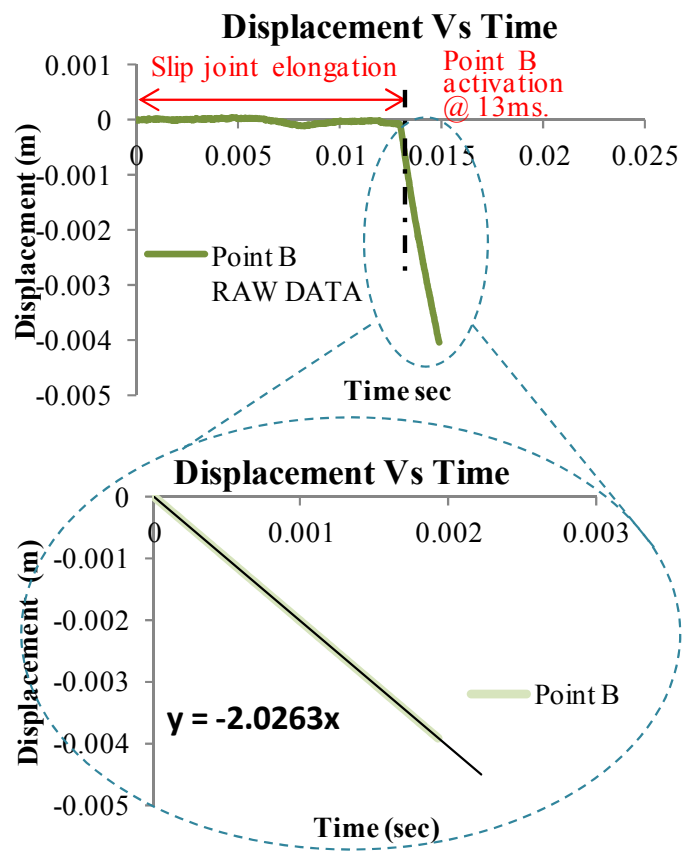

Figure 8: Specimens deformation (using targets $(\mathrm{A}, \mathrm{B})$ )

It should be noted that from both the figures (Figure 7 and Figure 8) time at which specimen starts deforming remain consistent. In Figure 8, relative displacement of point B with respect to point $\mathrm{A}$ is highly linear for the raw data. Therefore, the current experimental setup is suitable to conduct high strain rate (quasi-static) material

\section{Anand Viscoplastic Model}

Anand developed a constitutive equation for ratedependent deformation of metals at high temperature. Although its original purpose is represent the deformation of hot-working of steels and other structural metals, it has been adopted successfully to describe the Viscoplastic behavior of solder materials. This model unifies the creep and rate-dependent plastic behavior of the solder by making use of a stress equation, a flow equation, and an evolution equation. In addition, this model needs no explicit yield condition and no loading or unloading criterion. In uniaxial loading case (one dimension), stress equation can be described by

$\sigma=\mathrm{cs} ; \mathrm{c}<1$

where $\mathrm{c}(\mathrm{c}<1)$ is a function of strain rate and temperature, $\mathrm{s}$ is the internal valuable.

$\mathrm{c}=\left(\dot{\varepsilon}_{\mathrm{p}}, \mathrm{T}\right)=\left(\frac{1}{\xi}\right) \sinh ^{-1}\left\{\left[\frac{\dot{\varepsilon}_{\mathrm{p}}}{\mathrm{A}} \exp \left(\frac{\mathrm{Q}}{\mathrm{RT}}\right)\right]^{\mathrm{m}}\right\}$

where $i$ is the inelastic strain rate, $\xi$ is the multiplier of stress, A is the pre-exponential factor, Q is the activation energy, $\mathrm{T}$ is the absolute temperature, $\mathrm{R}$ is the universal gas constant, and $\mathrm{m}$ is the strain rate sensitivity. Substituting Equation (2) in Equation (1): $\sigma=\left(\frac{\mathrm{s}}{\xi}\right) \sinh ^{-1}\left\{\left[\frac{\dot{\varepsilon}_{\mathrm{p}}}{\mathrm{A}} \exp \left(\frac{\mathrm{Q}}{\mathrm{RT}}\right)\right]^{\mathrm{m}}\right\}$

Based on this equation, solving for $\dot{\varepsilon}_{\mathrm{p}}$ which yields the flow equation:

$\dot{\varepsilon}_{\mathrm{p}}=\mathrm{A} \exp \left(-\frac{\mathrm{Q}}{\mathrm{RT}}\right)\left[\sinh \left(\xi \frac{\sigma}{\mathrm{s}}\right)\right]^{1 / \mathrm{m}}$

where $\mathrm{s}$ is the internal variable, $\dot{\mathrm{s}}$ is assumed to be this form

$\dot{\mathrm{s}}=\left\{\mathrm{h}_{0}(|\mathrm{~B}|)^{\mathrm{a}} \frac{\mathrm{B}}{|\mathrm{B}|}\right\} \dot{\varepsilon}_{\mathrm{p}} ;(\mathrm{a}>1)$

where,

$\mathrm{B}=1-\frac{\mathrm{S}}{\mathrm{S}^{*}}$

and,

$\mathrm{s}^{*}=\hat{\mathrm{s}}\left(\frac{\dot{\varepsilon}_{\mathrm{p}}}{\mathrm{A}} \exp \left(\frac{\mathrm{Q}}{\mathrm{RT}}\right)\right)^{\mathrm{n}}$

where $\mathrm{h}_{0}$ is the hardening or softening constant, $\mathrm{a}(\mathrm{a}>1)$ is the strain rate sensitivity of hardening or softening process. The quantity $\mathrm{s}^{*}$ represents a saturation value of deformation resistance $\mathrm{s}$, associated with a set of given temperature and strain rate. $\hat{s}$ is a coefficient, and $\mathrm{n}$ is the strain rate sensitivity of the saturation value of deformation resistance. For $\mathrm{s}<\mathrm{s}^{*}, \mathrm{~B}>0$ from Equation (6). Then, Equation (5) can be simplify as,

$\mathrm{ds}=\mathrm{h}_{0}\left(1-\frac{\mathrm{s}}{\mathrm{s}^{*}}\right)^{\mathrm{a}} \mathrm{d} \varepsilon_{\mathrm{p}}$

Integrate on both sides to yield

$\mathrm{s}=\mathrm{s}^{*}-\left\{\left(\mathrm{s}^{*}-\mathrm{s}_{0}\right)^{(1-\mathrm{a})}+(\mathrm{a}-1)\left[\mathrm{h}_{0}\left(\mathrm{~s}^{*}\right)^{-\mathrm{a}} \varepsilon_{\mathrm{p}}\right]\right\}^{1 / 1-\mathrm{a}}$

where $s(0)=s_{0}$ is the initial value of $s$. Substituting Equation (7) in Equation (9):

$$
\begin{aligned}
& \mathrm{s}=\hat{\mathrm{s}}\left(\frac{\dot{\varepsilon}_{\mathrm{p}}}{\mathrm{A}} \exp \left(\frac{\mathrm{Q}}{\mathrm{RT}}\right)\right)^{\mathrm{n}} \\
&\left.-\left\{\hat{\mathrm{s}}\left(\frac{\dot{\varepsilon}_{\mathrm{p}}}{\mathrm{A}} \exp \left(\frac{\mathrm{Q}}{\mathrm{RT}}\right)\right)^{\mathrm{n}}-\mathrm{s}_{0}\right]^{1-\mathrm{a}}\right]^{1 / 1-\mathrm{a}} \\
&+(\mathrm{a}-1)\left[\mathrm{h}_{0}\left[\hat{\mathrm{s}}\left(\frac{\dot{\varepsilon}_{\mathrm{p}}}{\mathrm{A}} \exp \left(\frac{\mathrm{Q}}{\mathrm{RT}}\right)\right)^{\mathrm{n}}\right]^{-\mathrm{a}} \varepsilon_{\mathrm{p}}\right]
\end{aligned}
$$

Substituting Equation (10) in Equation (3) to get the final version of stress-strain relation: 


$$
\begin{aligned}
& \sigma=\left(\frac{1}{\xi}\right) \sinh ^{-1}\left\{\left[\frac{\dot{\varepsilon}_{\mathrm{p}}}{\mathrm{A}} \exp \left(\frac{\mathrm{Q}}{\mathrm{RT}}\right)\right]^{\mathrm{m}}\right\} \\
& \left\{\begin{array}{l}
\hat{\mathrm{s}}\left(\frac{\dot{\varepsilon}_{\mathrm{p}}}{\mathrm{A}} \exp \left(\frac{\mathrm{Q}}{\mathrm{RT}}\right)\right)^{\mathrm{n}} \\
-\left\{\hat{\mathrm{s}}\left(\frac{\dot{\varepsilon}_{\mathrm{p}}}{\mathrm{A}} \exp \left(\frac{\mathrm{Q}}{\mathrm{RT}}\right)\right)^{\mathrm{n}}-\mathrm{s}_{0}\right]^{1-\mathrm{a}} \\
+(\mathrm{a}-1)\left[\mathrm{h}_{0}\left[\hat{\mathrm{s}}\left(\frac{\dot{\varepsilon}_{\mathrm{p}}}{\mathrm{A}} \exp \left(\frac{\mathrm{Q}}{\mathrm{RT}}\right)\right)^{\mathrm{n}}\right]^{-\mathrm{a}}\right] \varepsilon^{1 / 1-\mathrm{a}}
\end{array}\right\}
\end{aligned}
$$

From the final expression of stress-strain function, nine material constants of the unified rate dependent Anand model have been included: $\mathrm{A}, \xi, \mathrm{Q} / \mathrm{R}, \mathrm{m}, \mathrm{h}_{0}, \mathrm{a}, \mathrm{s}_{0}, \hat{\mathrm{s}}$, and $\mathrm{n}$. The set of Anand constitutive equations cannot only account for the physical phenomena of strain-rate and temperature sensitivity, but also strain rate history effects, isotropic strain-hardening and the restoration process of dynamic recovery. The Ultimate Tensile Strength (UTS) can be attained by simply assuming that $\varepsilon_{\mathrm{p}}$ goes to infinity.

$$
\begin{aligned}
\sigma^{*}=\mathrm{UTS}=\left.\sigma\right|_{\varepsilon_{\mathrm{p}} \rightarrow \infty}= & \frac{\hat{\mathrm{s}}}{\xi}\left[\frac{\dot{\varepsilon}_{\mathrm{p}}}{\mathrm{A}} \exp \left(\frac{\mathrm{Q}}{\mathrm{RT}}\right)\right]^{\mathrm{n}} \\
& \sinh ^{-1}\left[\frac{\dot{\varepsilon}_{\mathrm{p}}}{\mathrm{A}} \exp \left(\frac{\mathrm{Q}}{\mathrm{RT}}\right)\right]^{\mathrm{m}}
\end{aligned}
$$

Substituting this maximum tensile stress back in Equation (11) and rewritten as

$$
\sigma=\sigma^{*}-\left[\left(\sigma^{*}-\mathrm{cs}_{0}\right)^{1-\mathrm{a}}+(\mathrm{a}-1)\left\{\operatorname{ch}_{0}\left(\sigma^{*}\right)^{-\mathrm{a}}\right\} \varepsilon_{\mathrm{p}}\right]^{1 / 1-\mathrm{a}}
$$

\section{Anand Constitutive Model Parameter Estimation}

In order to estimate the nine material parameters to represent constitutive equations, tensile test have been conducted in a wide range of strain rates and temperatures. High speed data acquiring system can provide stress and strain data in each particular condition. The data has been fit by non-linear regression method called the Levenberg-Marquardt Algorithm. Details on the algorithm can be found in [Madsen $2004^{21}$, Lourakis, $2005^{22}$, Nielsen 1999 ${ }^{23}$ ]. The Levenberg-Marquardt method is combination of steepest descent and the GaussNewton method. It is comparatively more robust because it converges to the solution even if it starts very far off the final minimum. The nine parameters of the Anand model calculated using this method include $\mathrm{A}, \xi, \mathrm{Q} / \mathrm{R}, \mathrm{m}, \mathrm{h}_{0}$, a, $\mathrm{s}_{0}, \hat{\mathrm{s}}$ and $\mathrm{n}$. From the measured stress and strain data, the value of the ultimate tensile stress can be calculated for several strain rates and temperatures. Furthermore, the stress -strain curve in each specific temperature and strain rate condition can be modified to stress-plastic strain curve by simply converting the total strain to plastic strain. These nine parameters can be obtained by the following procedures.

1. Equation (12) should be employed to fit saturation stress vs. strain rate and temperature data to determine the value of the parameters $A, n, Q / R$, $\mathrm{m}, \hat{\mathrm{s}} / \xi$.

2. Determination of $\xi$ and $\hat{\mathrm{s}}$. The parameter $\xi$ was selected such that the ratio of $\sigma / \mathrm{s}$ is less than unity and then $\hat{\mathbf{S}}$ is calculated by the combined term $\hat{\mathrm{s}} / \xi$ which has been decided in step. 1

3. Equation (13) has been applied to fit stress vs. plastic strain data at different strain rate and temperatures to determine the values of parameters $\mathrm{h}_{0}, \mathrm{a}, \mathrm{s}_{0}$

\section{Experimental Matrix}

Uniaxial tensile testing has been conducted at 5 different temperatures $\left(\mathrm{T}=25,50,75,100,125^{\circ} \mathrm{C}\right)$ and 4 different strain rates $(\dot{\varepsilon}=10,35,50,75$ per sec) shown in Table 1 . The dimensions of the specimen and method to test those samples are the same as described earlier in this paper. For each set of test conditions, multiple samples were tested immediately after reflow process.

Table 1: Test matrix

\begin{tabular}{|c|c|c|c|c|}
\hline \multirow{2}{*}{$\mathrm{T}\left({ }^{\circ} \mathrm{C}\right)$} & \multicolumn{4}{|c|}{ strain rate (per sec) } \\
\cline { 2 - 5 } & 10 & 35 & 50 & 75 \\
\hline 25 & $\mathrm{x}$ & $\mathrm{x}$ & $\mathrm{x}$ & $\mathrm{x}$ \\
\hline 50 & $\mathrm{x}$ & $\mathrm{x}$ & $\mathrm{x}$ & $\mathrm{x}$ \\
\hline 75 & $\mathrm{x}$ & $\mathrm{x}$ & $\mathrm{x}$ & $\mathrm{x}$ \\
\hline 100 & $\mathrm{x}$ & $\mathrm{x}$ & $\mathrm{x}$ & $\mathrm{x}$ \\
\hline 125 & $\mathrm{x}$ & $\mathrm{x}$ & $\mathrm{x}$ & $\mathrm{x}$ \\
\hline
\end{tabular}

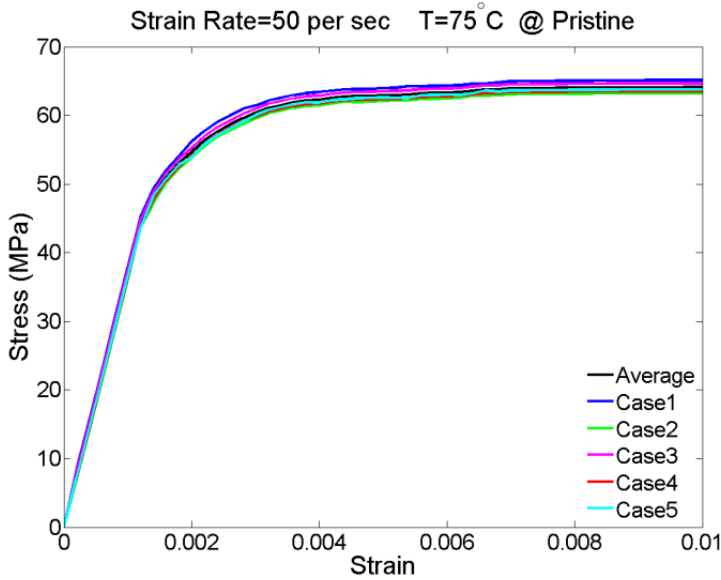

Figure 9: Method for Averaging High Strain Rate Data. Representative data shown for SAC305

Measured data were averaged to obtain the nominal material response at each particular test condition, as 
shown in Figure 9. Then the optimal values of the nine Anand parameters for SAC105 and SAC305 materials have been extracted based on the experimental stressstrain curves over those wide range temperatures and strain rates.

\section{SAC105 Properties}

The mechanical properties for the SAC105 solder have been extracted from the Stress-Strain curves in Figure 10 to Figure 13. Material properties for SAC105 solder alloys show sensitivity to strain rates and temperature. Figure 14 and Figure 15 illustrates the variation of initial effective Elastic Modulus (E), and Ultimate Tensile Strength (UTS) with temperature and strain rate.

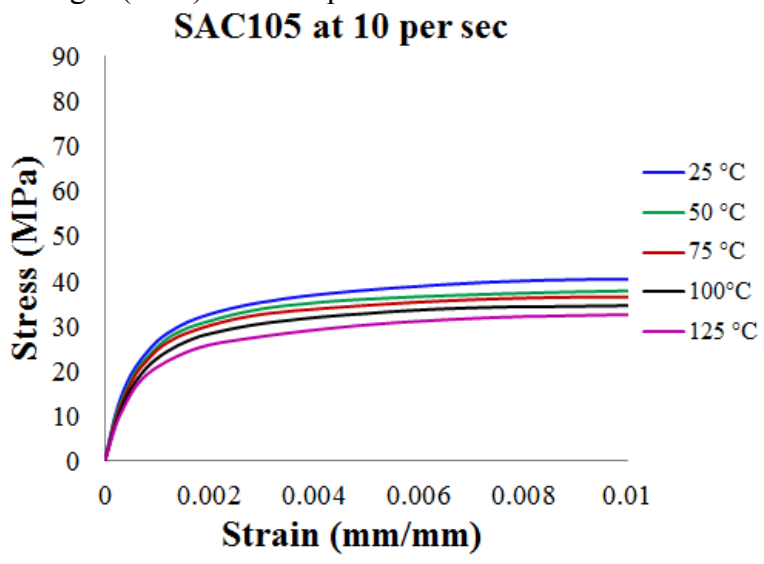

Figure 10: Stress vs Strain for SAC105@10 per sec Strain Rate.

Table 2: SAC105 at $10 / \mathrm{sec}$

\begin{tabular}{|c|c|c|}
\hline $\mathrm{T}\left({ }^{\circ} \mathrm{C}\right)$ & $\mathrm{E}(\mathrm{GPa})$ & UTS $(\mathrm{MPa})$ \\
\hline 25 & 35 & 40.4 \\
\hline 50 & 33.2 & 37.8 \\
\hline 75 & 32.3 & 36.5 \\
\hline 100 & 29.7 & 34.6 \\
\hline 125 & 27.7 & 32.6 \\
\hline
\end{tabular}

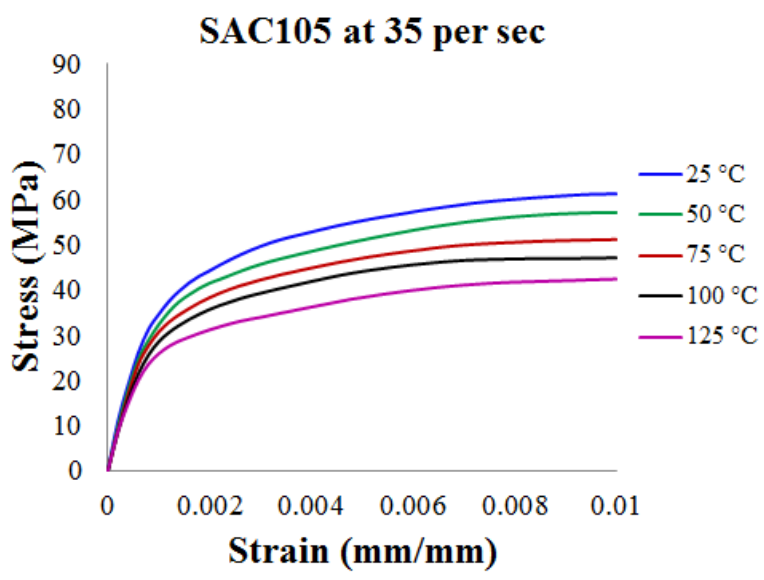

Figure 11: Stress vs Strain for SAC105@35 per sec Strain Rate.
Table 3: SAC 105 at $35 / \mathrm{sec}$

\begin{tabular}{|c|c|c|}
\hline $\mathrm{T}\left({ }^{\circ} \mathrm{C}\right)$ & $\mathrm{E}(\mathrm{GPa})$ & UTS $(\mathrm{MPa})$ \\
\hline 25 & 38.8 & 61.2 \\
\hline 50 & 36.2 & 57.1 \\
\hline 75 & 34.9 & 51.1 \\
\hline 100 & 31.9 & 47.0 \\
\hline 125 & 29.2 & 42.4 \\
\hline
\end{tabular}

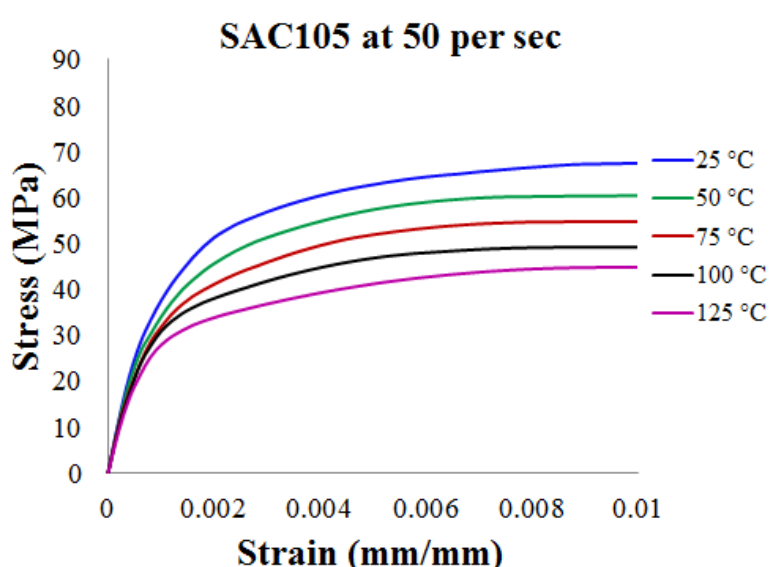

Figure 12: Stress vs Strain for SAC105@50 per sec Strain Rate.

Table 4: SAC 105 at $50 / \mathrm{sec}$

\begin{tabular}{|c|c|c|}
\hline $\mathrm{T}\left({ }^{\circ} \mathrm{C}\right)$ & $\mathrm{E}(\mathrm{GPa})$ & $\mathrm{UTS}(\mathrm{MPa})$ \\
\hline 25 & 41.5 & 67.4 \\
\hline 50 & 37.7 & 60.3 \\
\hline 75 & 35.1 & 54.6 \\
\hline 100 & 34.3 & 49.1 \\
\hline 125 & 31.2 & 44.7 \\
\hline
\end{tabular}

SAC105 at 75 per sec

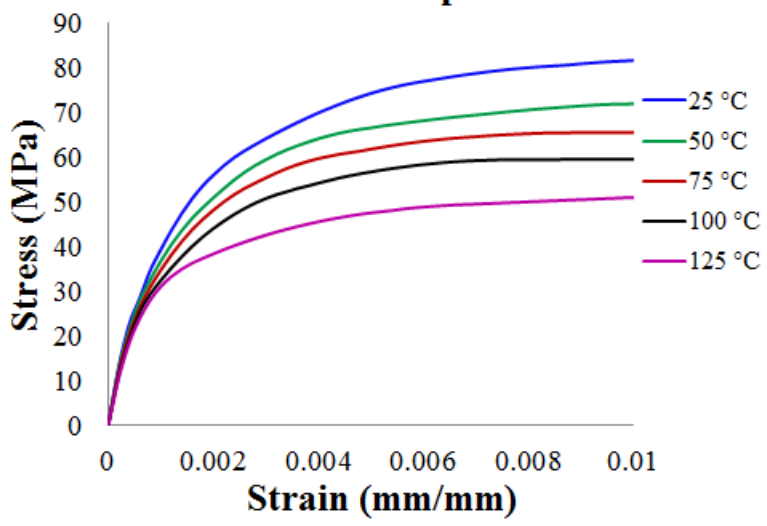

Figure 13: Stress vs Strain for SAC105@75 per sec Strain Rate.

Table 5: SAC105 at $75 / \mathrm{sec}$

\begin{tabular}{|c|c|c|}
\hline $\mathrm{T}\left({ }^{\circ} \mathrm{C}\right)$ & $\mathrm{E}(\mathrm{GPa})$ & $\mathrm{UTS}(\mathrm{MPa})$ \\
\hline 25 & 42.2 & 81.5 \\
\hline 50 & 40 & 71.7 \\
\hline 75 & 37.9 & 65.4 \\
\hline 100 & 36.2 & 59.3 \\
\hline 125 & 34.5 & 50.8 \\
\hline
\end{tabular}


Elastic Modulus vs Temperature

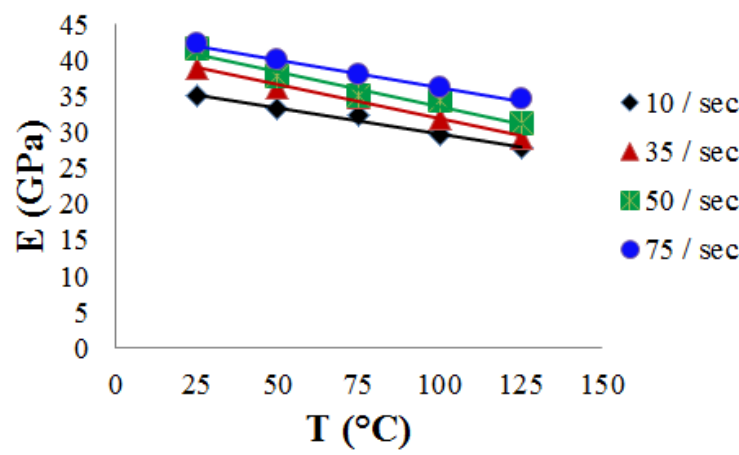

Figure 14: Effect of Operating Temperature and Strain Rate on Elastic Modulus for SAC105.

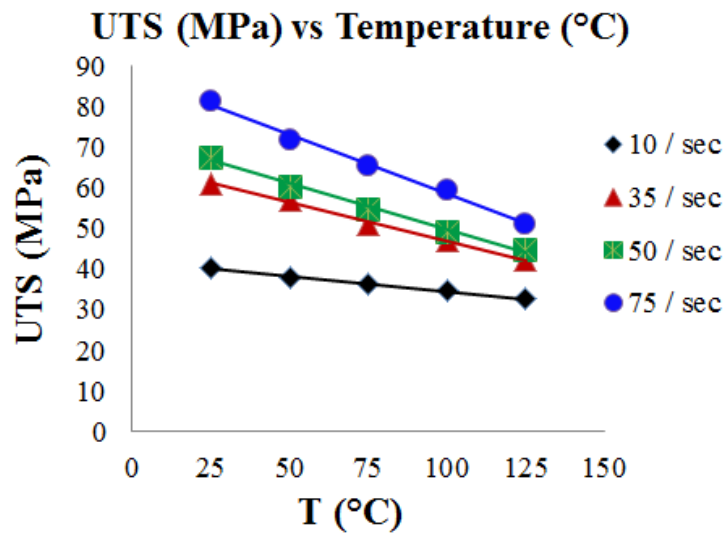

Figure 15: Effect of Operating Temperature and strain rate on UTS for SAC105.

Figure 14 shows that Elastic modulus decrease as the testing temperature increases for all strain rates and Elastic modulus increase as the testing strain rates increases for all testing temperature. Similarly, Figure 15 shows that UTS decrease as the testing temperature increases for all strain rates and UTS increase as the testing strain rates increases for all testing temperature.

\section{SAC305 Properties}

Figure 16-to-Figure 19 shows the measured stress-strain data for SAC305 over the 5 temperatures and 4 strain rates. All the mechanical properties of SAC305 have been extracted from the above curves shown in Figure 16-toFigure 19. Those material properties including the elastic modulus and the ultimate tensile strength (UTS) has been put in Table 6-to-Table 9. The Young's modulus and UTS (saturation stress) begin to decrease, once the temperature increased (Figure 20, Figure 21). All those material properties values have been plotted in Figure 22 and Figure 23 respectively. Furthermore, variations in different temperature at each particular strain rate condition have been fitted with a linear line.

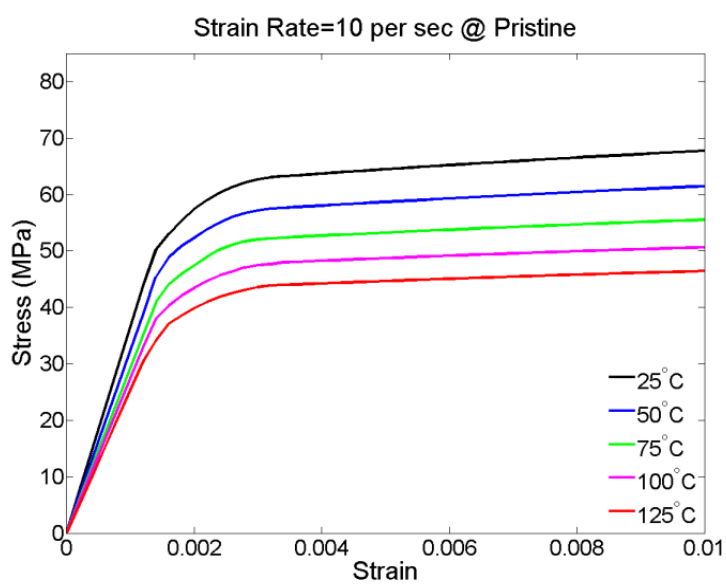

Figure 16: $\dot{\varepsilon}=10$ per sec for SAC305

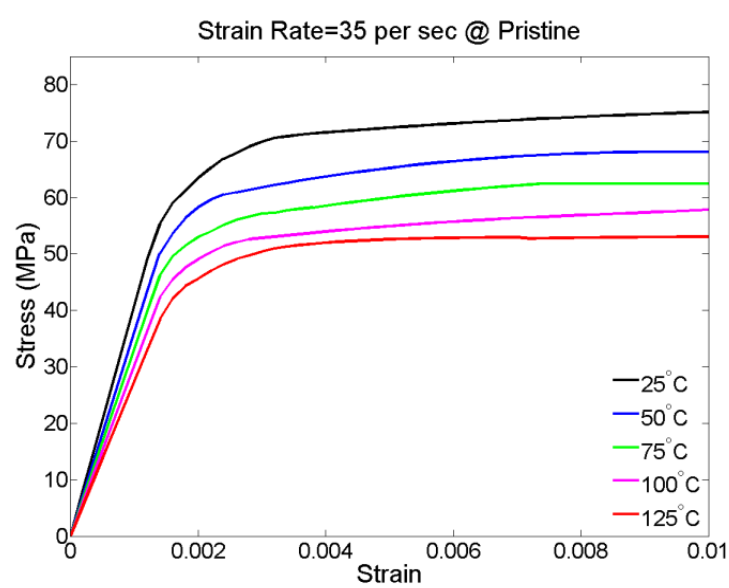

Figure 17: $\dot{\varepsilon}=35$ per sec for SAC305

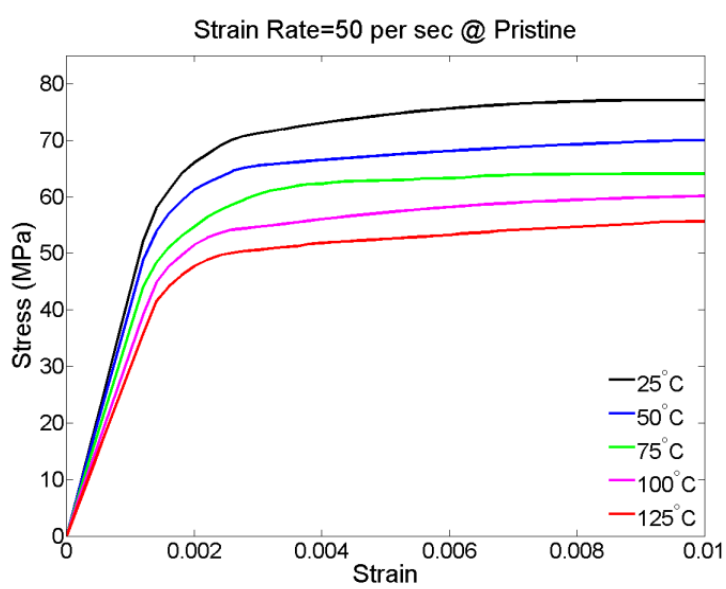

Figure 18: $\dot{\varepsilon}=50$ per sec for SAC305 


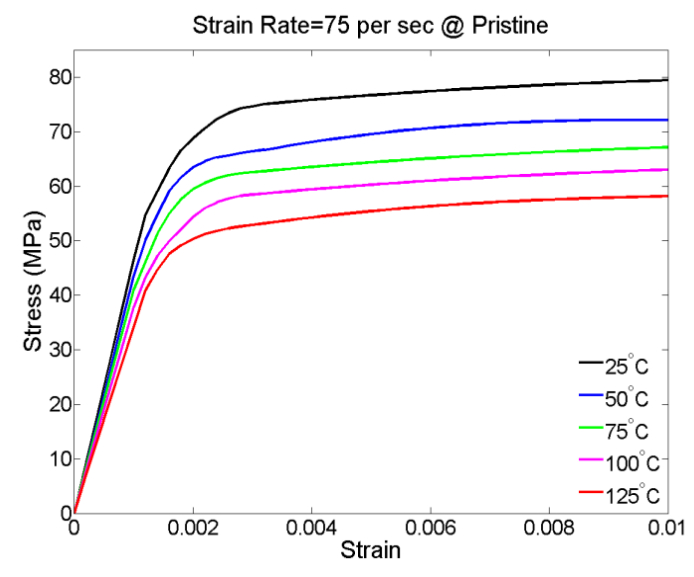

Figure 19: $\dot{\varepsilon}=75$ per sec for SAC305

Table 6: Material properties of SAC305 at 10 per sec

\begin{tabular}{|c|c|c|}
\hline \multicolumn{3}{|c|}{ Strain Rate=10 per sec } \\
\hline $\mathrm{T}\left({ }^{\circ} \mathrm{C}\right)$ & $\mathrm{E}(\mathrm{GPa})$ & UTS $(\mathrm{MPa})$ \\
\hline 25 & 36.57 & 67.73 \\
\hline 50 & 32.24 & 61.46 \\
\hline 75 & 29.23 & 55.51 \\
\hline 100 & 27.45 & 50.65 \\
\hline 125 & 25.36 & 46.44 \\
\hline
\end{tabular}

Table 7: Material properties of SAC305 at 35 per sec

\begin{tabular}{|c|c|c|}
\hline \multicolumn{3}{|c|}{ Strain Rate $=35$ per sec } \\
\hline $\mathrm{T}\left({ }^{\circ} \mathrm{C}\right)$ & $\mathrm{E}(\mathrm{GPa})$ & UTS $(\mathrm{MPa})$ \\
\hline 25 & 40.92 & 75.12 \\
\hline 50 & 36.2 & 68.09 \\
\hline 75 & 33.22 & 62.46 \\
\hline 100 & 30.3 & 57.81 \\
\hline 125 & 27.46 & 53.07 \\
\hline
\end{tabular}

Table 8: Material properties of SAC305 at 50 per sec

\begin{tabular}{|c|c|c|}
\hline \multicolumn{3}{|c|}{ Strain Rate $=50$ per sec } \\
\hline $\mathrm{T}\left({ }^{\circ} \mathrm{C}\right)$ & $\mathrm{E}(\mathrm{GPa})$ & UTS $(\mathrm{MPa})$ \\
\hline 25 & 43.51 & 77.09 \\
\hline 50 & 40.68 & 69.98 \\
\hline 75 & 36.77 & 64.09 \\
\hline 100 & 32.65 & 60.16 \\
\hline 125 & 29.87 & 55.64 \\
\hline
\end{tabular}

Table 9: Material properties of SAC305 at 75 per sec

\begin{tabular}{|c|c|c|}
\hline \multicolumn{3}{|c|}{ Strain Rate $=75$ per sec } \\
\hline $\mathrm{T}\left({ }^{\circ} \mathrm{C}\right)$ & $\mathrm{E}(\mathrm{GPa})$ & $\mathrm{UTS}(\mathrm{MPa})$ \\
\hline 25 & 46.48 & 79.44 \\
\hline 50 & 43.46 & 72.14 \\
\hline 75 & 40.92 & 67.12 \\
\hline 100 & 37.77 & 63.02 \\
\hline 125 & 34.12 & 58.18 \\
\hline
\end{tabular}

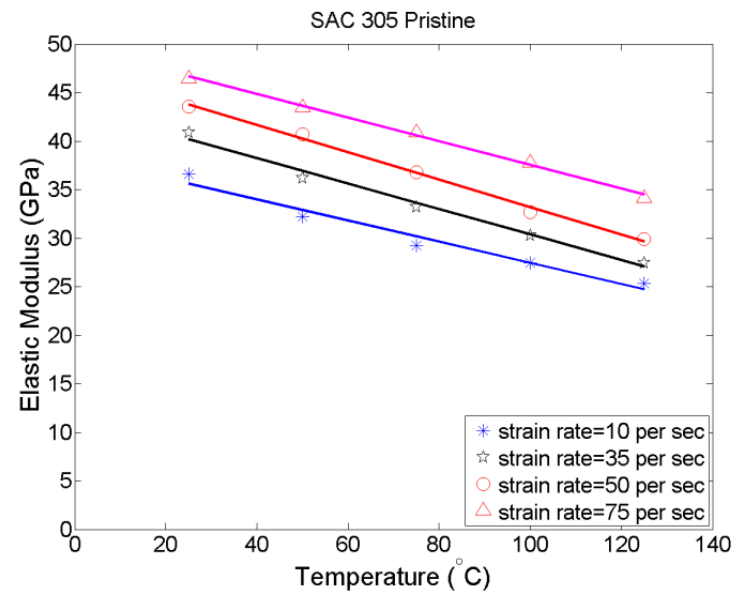

Figure 20: Effect of Temperature on Elastic Modulus

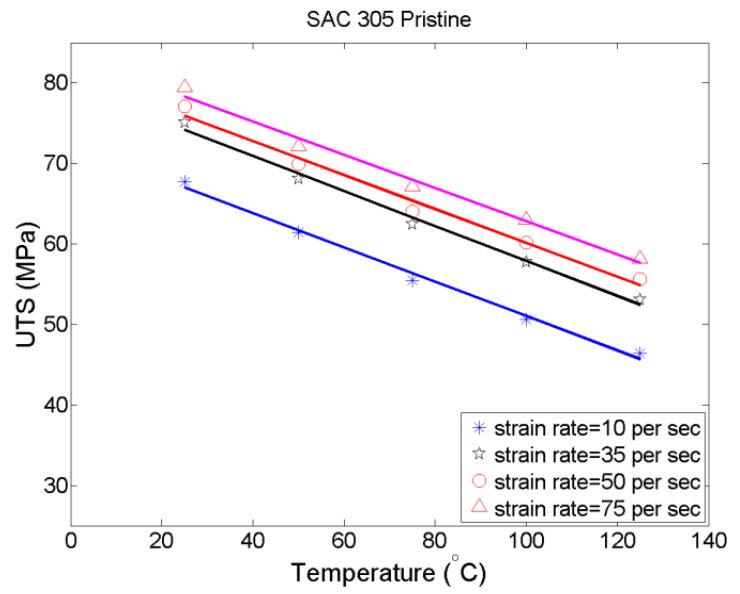

Figure 21: Effect of Temperature on the UTS

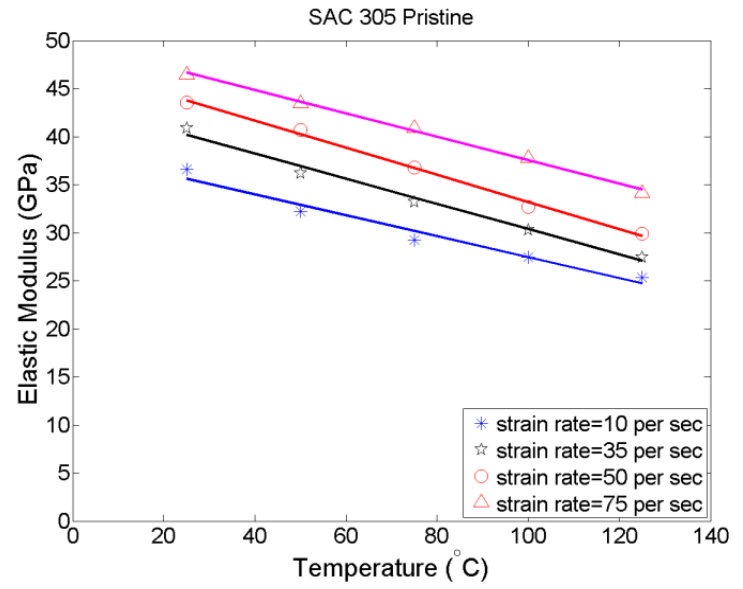

Figure 22: Elastic Modulus versus Strain Rate for SAC305 


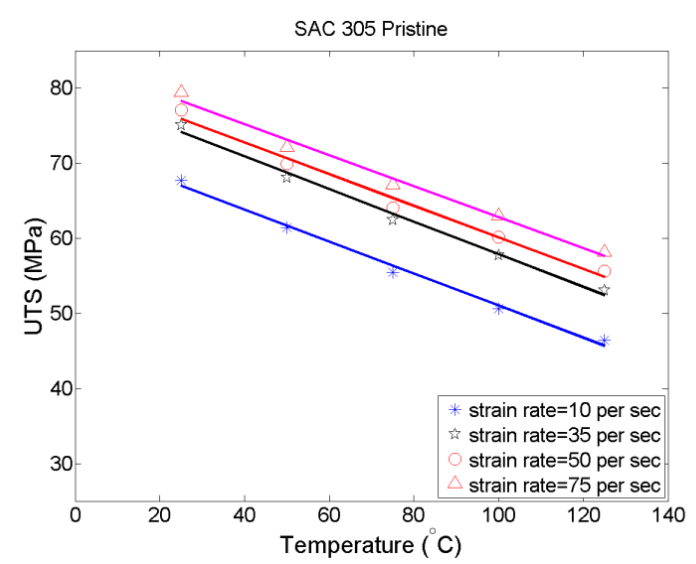

Figure 23: UTS versus Strain Rate for SAC305

\section{Determination of Anand Model Constants}

By using the procedures that discussed in section on Anand Viscoplasticity, all the nine Anand constants have been determined from the stress-strain curves of leadfree solders at different strain rates and temperatures conditions. Nonlinear regression fitting method has been used to fit all the data from these curves. In all the cases, goodness of fitting has been achieved to get great prediction for simulation. The extracted Anand constants for high strain rates are listed in Table 10.

Table 10: Anand Model Parameters of SAC105 and SAC305 without Aging

\begin{tabular}{|c|c|c|c|}
\hline $\begin{array}{c}\text { Anand } \\
\text { Contant }\end{array}$ & Units & SAC105 & SAC305 \\
\hline $\mathrm{s}_{0}$ & $\mathrm{MPa}$ & 2.45 & 1.56 \\
\hline $\mathrm{Q} / \mathrm{R}$ & $1 / \mathrm{k}$ & 5881 & 4461 \\
\hline $\mathrm{A}$ & Sec $^{-1}$ & 1366 & 993 \\
\hline$\xi$ & Dimensionless & 4.9 & 5.6 \\
\hline $\mathrm{m}$ & Dimensionless & 0.52 & 0.3959 \\
\hline $\mathrm{h} 0$ & $\mathrm{MPa}$ & 67682 & 77930 \\
\hline$\hat{\mathrm{s}}$ & $\mathrm{MPa}$ & 28.1 & 78.4 \\
\hline $\mathrm{n}$ & Dimensionless & 0.01 & $1.25 \mathrm{E}-03$ \\
\hline $\mathrm{a}$ & Dimensionless & 1.46 & 1.096 \\
\hline
\end{tabular}

\section{Model Verification}

\section{SAC105 Model Validation}

The Anand model stress-strain curves from the model predictions have been correlated with the experimental measurements of the stress-strain curve to determine the goodness of fit. Figure 24 to Figure 27 show the correlation between the Anand model predictions for the stress-strain curves and the experimental data for the 5 temperatures and 4 strain rates considered. In all cases, good correlation is obtained indicating that the extracted Anand model parameters provide a good fit to the experimental data.

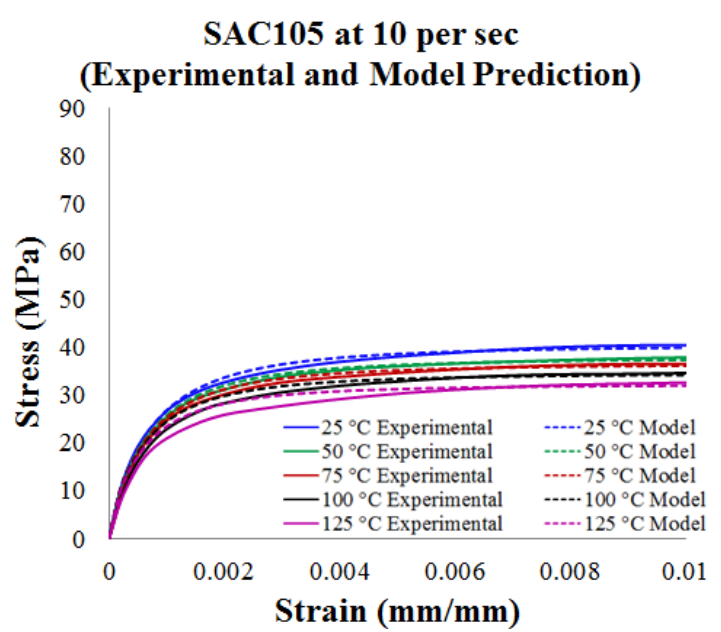

Figure 24: Model Predictions vs Experimental StressStrain Curves for SAC105 at Strain Rate of 10 per sec

SAC105 at 35 per sec

(Experimental and Model Prediction)

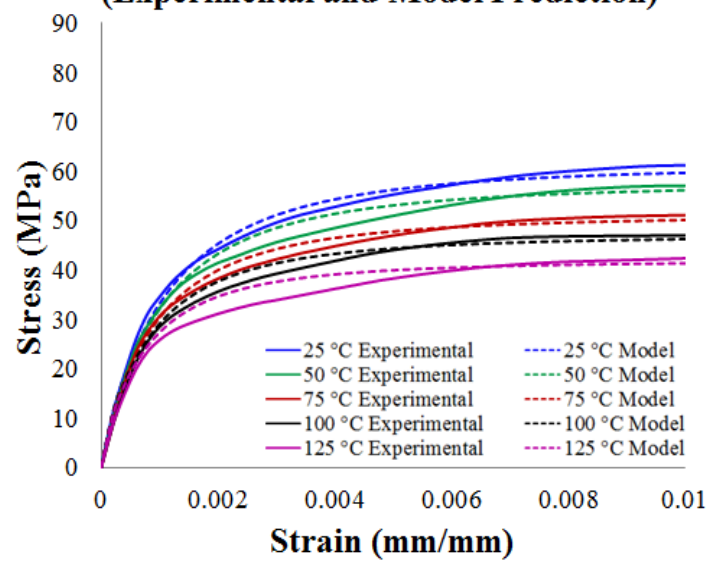

Figure 25: Model Predictions vs Experimental StressStrain Curves for SAC105 at strain rate of 35 per sec.

SAC105 at 50 per sec

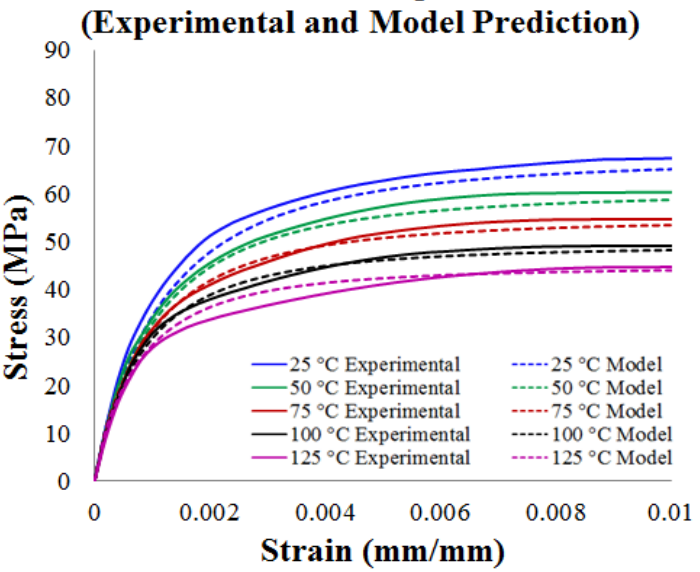

Figure 26: Model Predictions vs Experimental StressStrain Curves for SAC105 at strain rate of 50 per sec 


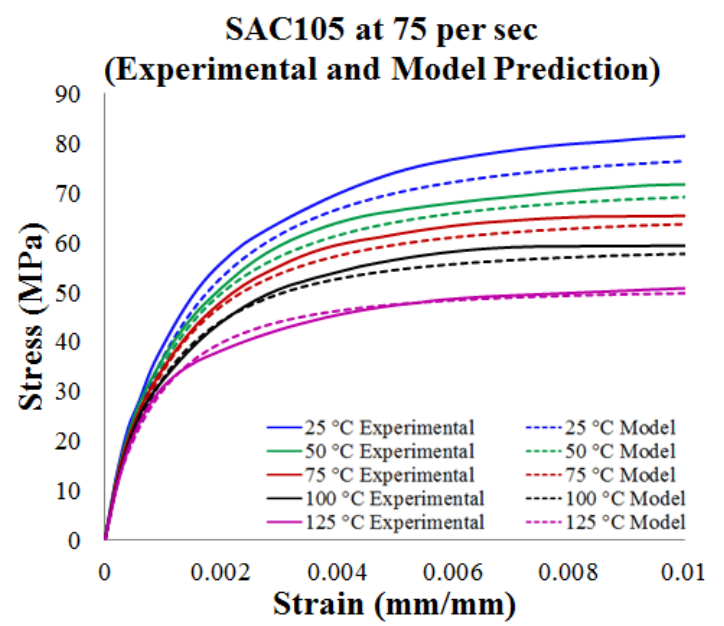

Figure 27: Model Predictions vs Experimental StressStrain Curves for SAC105 at strain rate of 75 per sec.

SAC305 Model Validation

Since all the parameters have been determined from the above procedures, constitutive relations to describe the mechanical properties of SAC305 can be achieved. It is possible to use this constitutive model to predict the behavior of this lead-free solder at each particular temperature and strain rate.

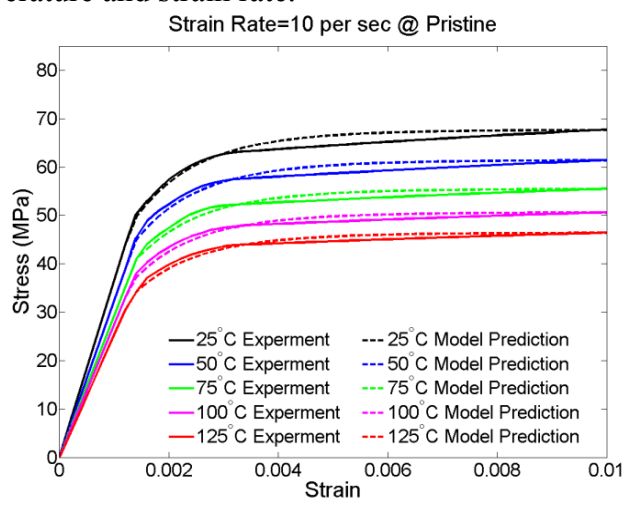

Figure 28: $\dot{\varepsilon}=10$ per sec for SAC305

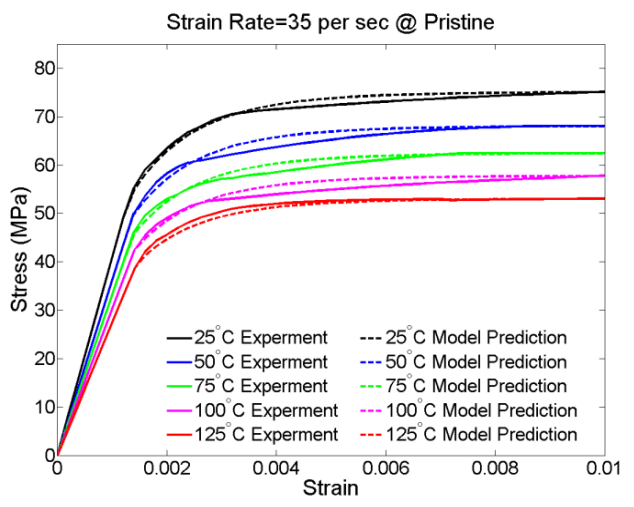

Figure 29: $\dot{\varepsilon}=35$ per sec for $\mathrm{SAC} 305$

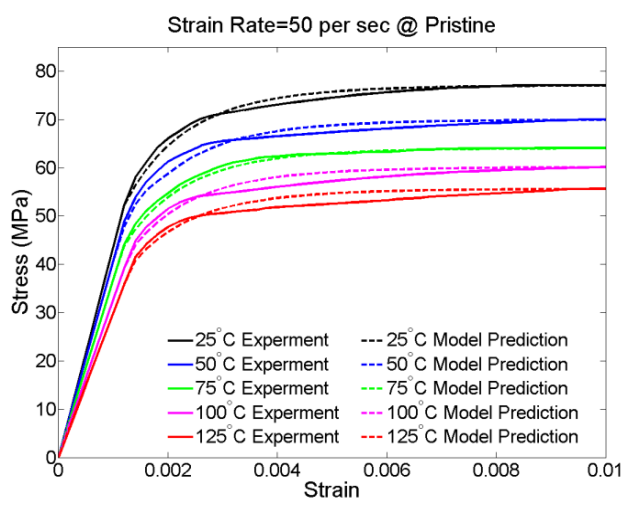

Figure 30: $\dot{\varepsilon}=50$ per sec for SAC 305 Strain Rate=75 per sec @ Pristine

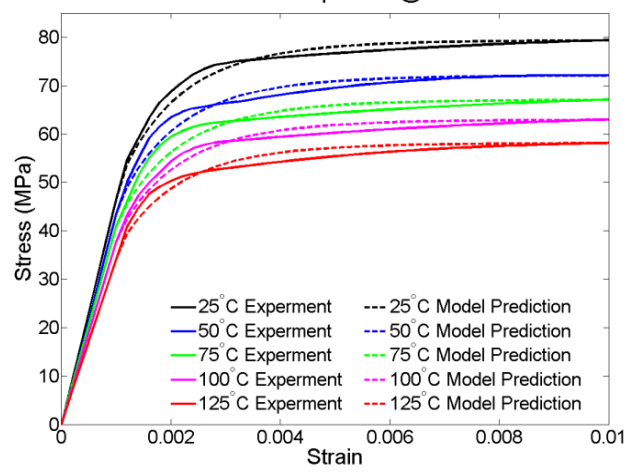

Figure 31: $\dot{\varepsilon}=75$ per sec for SAC305

All the stress-strain curves obtained in experiments have been correlated with the Anand Model in order to evaluate the goodness of fitting. Figure 28-to-Figure 31 illustrates the correlation between the experimental data and model prediction. In all the cases including 5 temperatures and 4 strain rates, good correlations have been performed.

10. Modeling of Transient Dynamics of Board Assemblies using Anand Viscoplasticity

ANSYS ${ }^{\mathrm{TM}}$ with implicit solver has been used to simulate the whole drop impact event. In order to capture the symmetric and the asymmetric transient mode shapes the complete board assembly has been modeled without any assumption of symmetry. The corner balls have been made with solid elements and the inner interconnects have been modeled using Timoshenko beam elements. The corner solder joints have been modeled using VISCO107 elements. The remaining package elements including the printed circuit board have been modeled using SOLID45 elements. The non-corner interconnects are modeled using BEAM188 elements. Figure 32 shows the finite element model for the complete board assembly. Figure 33 shows the close-up and the cut section of the electronic component on the printed circuit board assembly. 


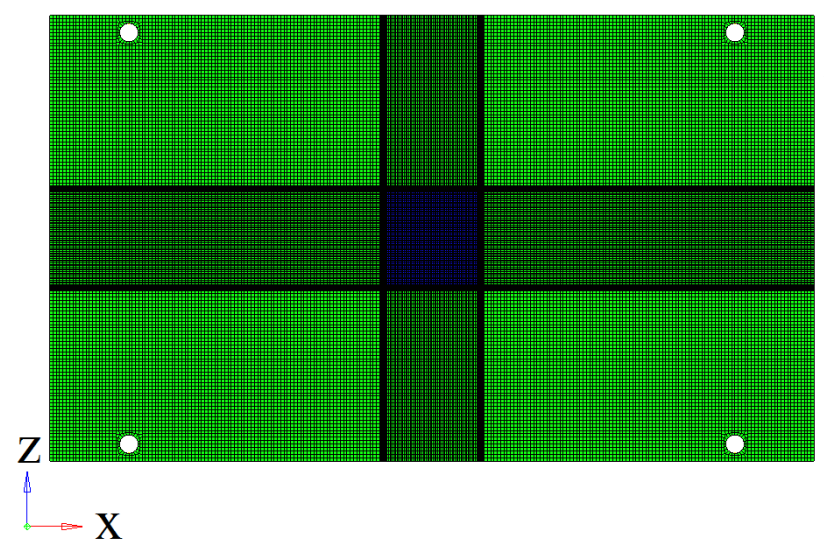

Figure 32: Finite Element Modeling of Test Board

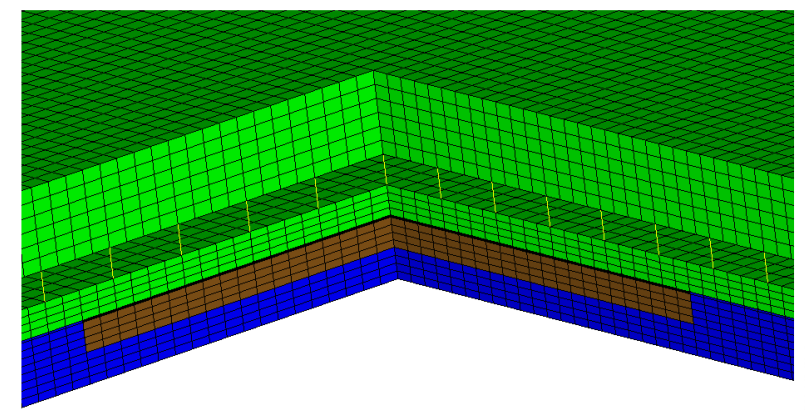
$\underset{\mathrm{Z}}{\mathrm{z}_{\mathrm{B}}^{\mathrm{y}}}$

Figure 33: Cut-Section of PBGA 324

\section{Boundary Conditions}

Input-G method has been used to analyze board-level drop test event. In this case, a large mass element has been attached to one of the nodes around the screw holes. The acceleration input which has been captured experimentally using a high-speed data-acquisition system is applied to the large mass node in the model. The product of the applied acceleration with the mass of the mass node give the magnitude of the applied force on the model. A shock pulse of $1500 \mathrm{~g}, 0.5 \mathrm{~ms}$ has been modeled on the board assembly. The acceleration plot in Figure 32 has been converted to force data by multiplying the acceleration with the magnitude of the large mass at the corner-hole node. The mass of the mass element has been chosen as a high multiple of the mass of the entire board assembly. The tabular force data that has been generated using this method has been applied as a boundary condition to the mass elements in the board assembly in order to apply the desired acceleration. Furthermore, in order to simulate the physical behavior of the non-corner interconnects, the rotational degrees-offreedom at the corners of the Timoshenko-beam elements have been constrained. The preconditioned gradient solver has been used to solve the shock-impact problem.

\section{Model Predictions}

Printed Circuit Board Displacement and Strain Field

The printed circuit board undergoes transient dynamic motion during and after mechanical shock impact. The large out-of-plane deformation causes the solder joints to experience deformation in tension and compression. High-speed imaging measurements of the printed circuit card assembly indicate that the maximum deformation is sustained at the center of the printed circuit card assembly (Figure 35 and Figure 37).

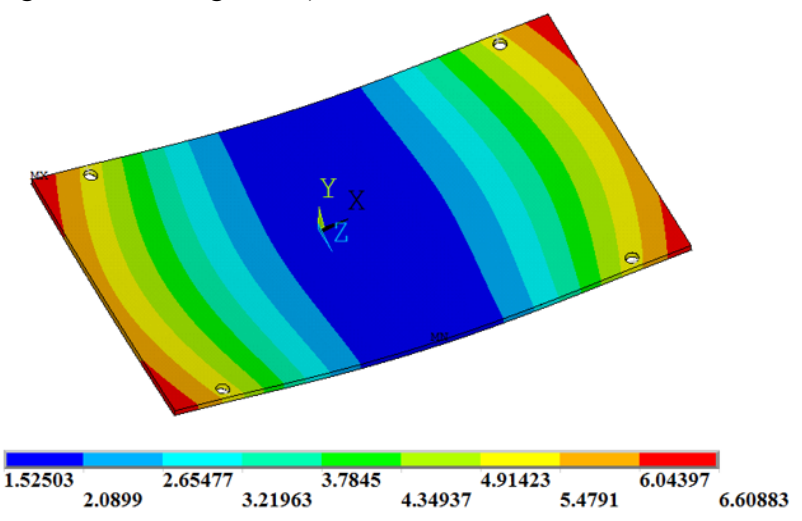

Figure 34: Maximum Downward Displacement Distribution of PCB in Simulation

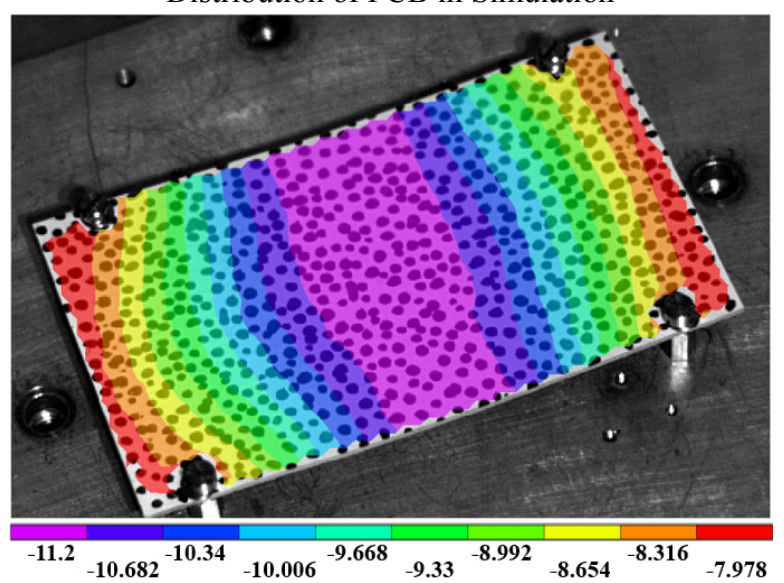

Figure 35: Maximum Downward Displacement Distribution of PCB in Experiment
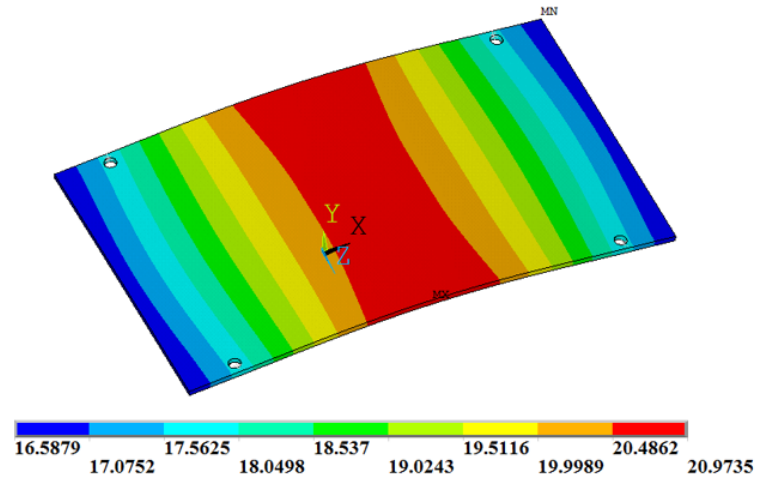

Figure 36: Maximum Upward Displacement Distribution of PCB in Simulation 


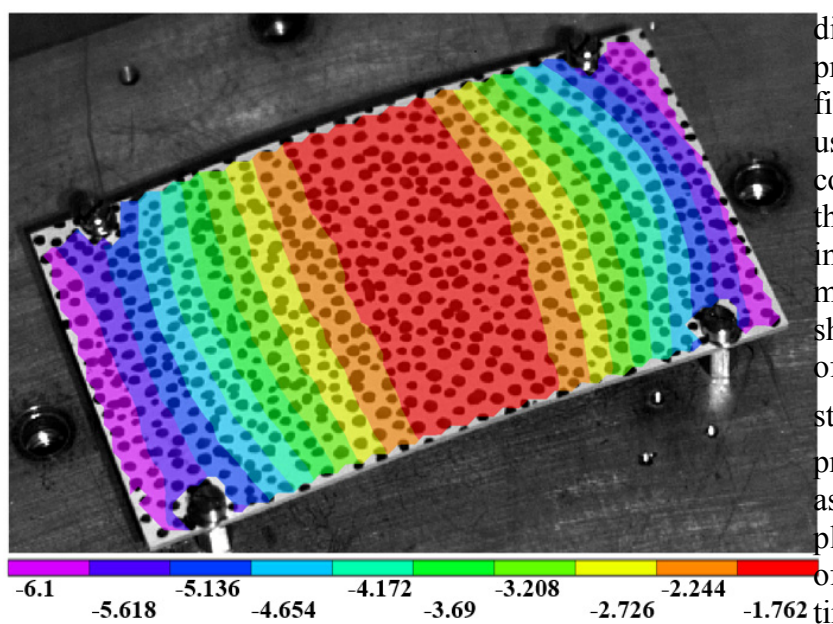

Figure 37: Maximum Upward Displacement Distribution of PCB in Experiment

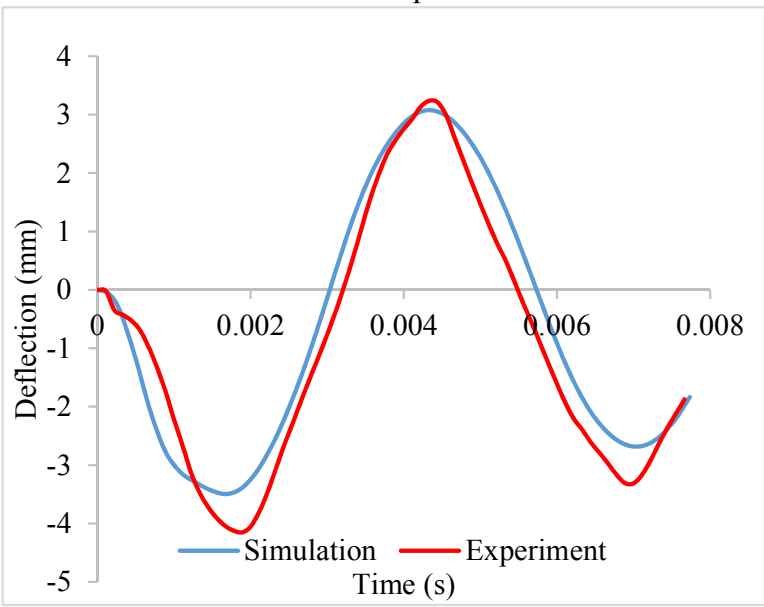

Figure 38: Displacement at the center of PCB

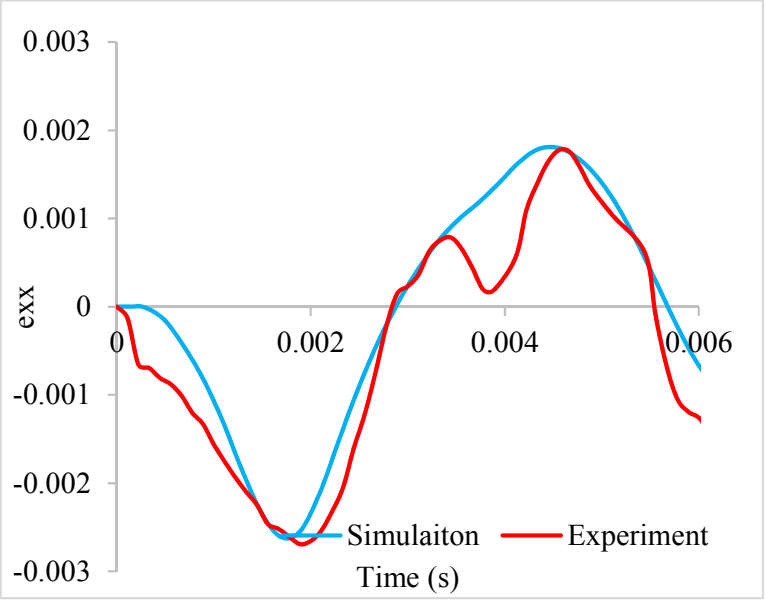

Figure 39: Strain at the center of PCB

Model predictions of the board assembly deflection during impact can be seen in Figure 34 and Figure 36. The model predictions of board deformation correlate well with the experimental measurement of the board assembly deformation during impact. The relative displacement between the screws of the supports and the printed circuit board have been computed from both the finite element model and the experimental measurements using digital image correlation. Figure 38 shows the correlation of the model predictions of deformation with the experimental measurements as a function of time after initial impact of the board assembly. The predicted and measured deformation history of the board assembly shows good correlation in time-period and the amplitude of the deformation. Furthermore, the in-plane normal strain $\left(\varepsilon_{\mathrm{xx}}\right)$ in the board assembly has been measured and predicted along the major axis of deformation of the board assembly (Figure 39). Model prediction of the normal inplane strain show good correlation with the measurement of transient strain from digital image correlation in both

\section{Prediction of Solder-Joint Strains and Stresses}

The transient stresses and strains in the solder joints have been extracted during and after impact. Figure 40 shows the $y$-stress in the solder joint $1.344 \mathrm{~ms}$ after impact when the maximum downward deformation of the printed circuit board assembly is encountered.

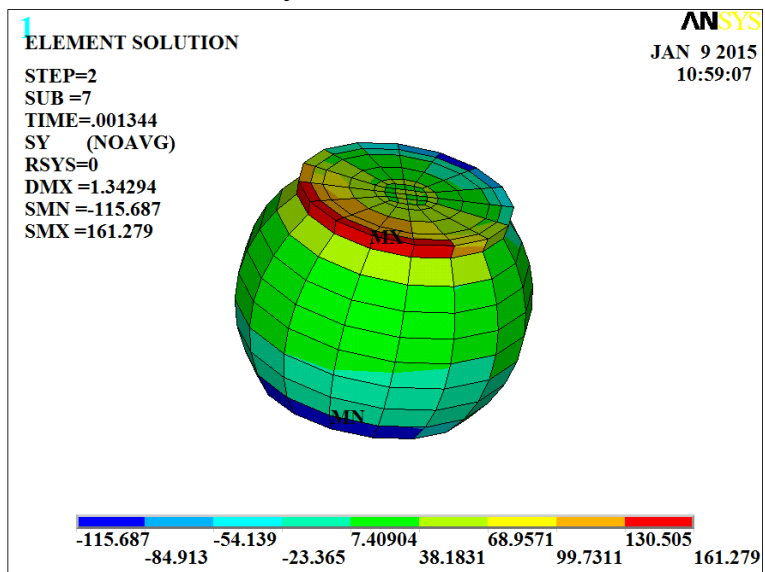

Figure 40: Stress Distribution of Critical Solder Ball at Maximum downward Deformation of PCB

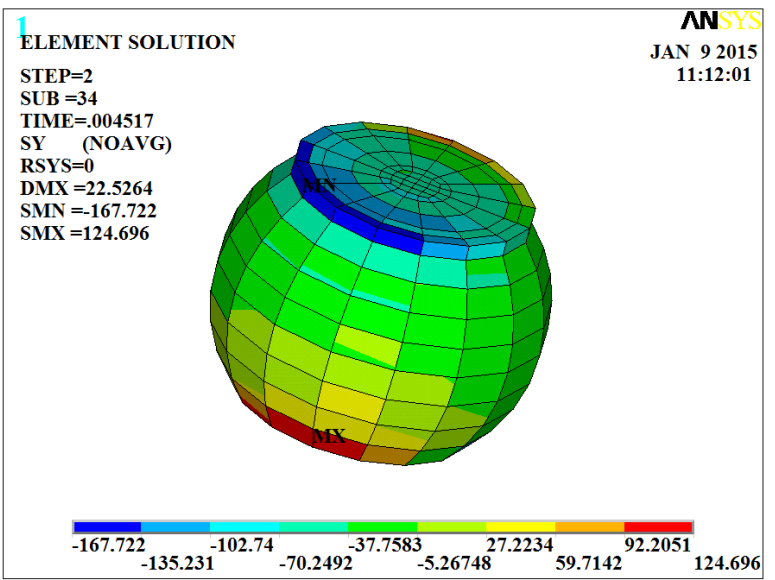

Figure 41: Stress Distribution of Critical Solder Ball at Maximum Upward Deformation of PCB 
The largest magnitude of the normal stress in the corner solder joint is at the SJ-Component pad interface. Figure 41 shows the y-stress in the solder joint at $4.517 \mathrm{~ms}$ after impact when the maximum deformation of the printed circuit board is encountered in the upward direction. The location of maximum normal y-stress has shifted to the interface of the solder joint of the copper pad of the printed circuit board at the instant of maximum upward deformation.

\section{Measures of Solder Joint Damage}

Three measures of solder joint damage have been assessed for damage computation during impact of the board assembly. The methods include - (1) magnitude of the highest normal $y$-strain in the highest strain CRITICAL ELEMENT in the corner solder joint (2) magnitude of the highest normal y-strain in the CENTER of the corner solder joint with the highest strain value (3) volume averaged value of normal y-strain. The volume averaging method is intended to reduce the sensitivity to mesh discretization. Only the top layer of the critical solder joint has been used to calculate the average values of the normal strain in the solder joint.

$\varepsilon_{\text {ave }}=\frac{\sum_{i=1}^{n} \varepsilon_{i} \cdot V_{i}}{\sum_{i=1}^{n} V_{i}}$

where $\varepsilon_{\text {ave }}$ is the average strain in the solder joint along the normal direction, $\mathrm{V}_{\mathrm{i}}$ is the volume of $\mathrm{i}^{\text {th }}$ element, $\varepsilon_{\mathrm{i}}$ is the strain value of $i^{\text {th }}$ element along the normal direction.

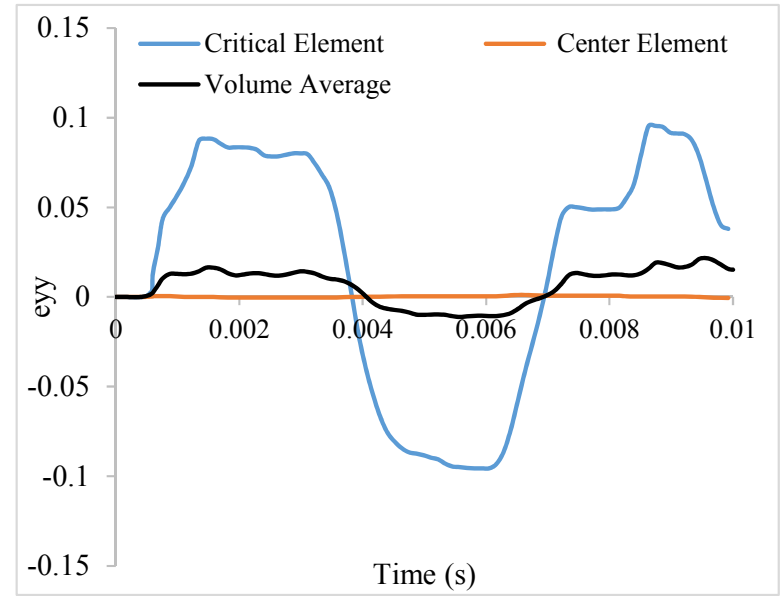

Figure 42: Strain History of the Critical Solder Ball

Figure 42 shows the comparison of the normal y-strain in the solder joint from the three-methods including critical element, center element, and the volume average. The volume averaged values of strain provide the balance between sensitivity to the mesh discretization while providing sensitivity to damage sustained due to mechanical shock. The center element has lower sensitivity to the shock load. The critical element value is very sensitive to mesh discretization.

Plastic Work of Critical Solder Joint

In addition to strains, the plastic work in the solder joints was studied by calculating the volume average of the plastic work in the top layer of the elements using the following equation:

$\mathrm{W}_{\mathrm{ave}}=\frac{\sum_{\mathrm{i}=1}^{\mathrm{n}} \mathrm{W}_{\mathrm{i}} \cdot \mathrm{V}_{\mathrm{i}}}{\sum_{\mathrm{i}=1}^{\mathrm{n}} \mathrm{V}_{\mathrm{i}}}$

where, $\mathrm{W}_{\mathrm{ave}}$ is the accumulated average viscoplastic strain energy at the interface elements, and $V_{i}$ is the volume of $i^{\text {th }}$ element. Figure 43 shows the evolution of the volume averaged plastic work in the corner solder balls as a function of time after impact of the board assembly subjected to $1500 \mathrm{~g}, 0.5 \mathrm{~ms}$ half-sine pulse.

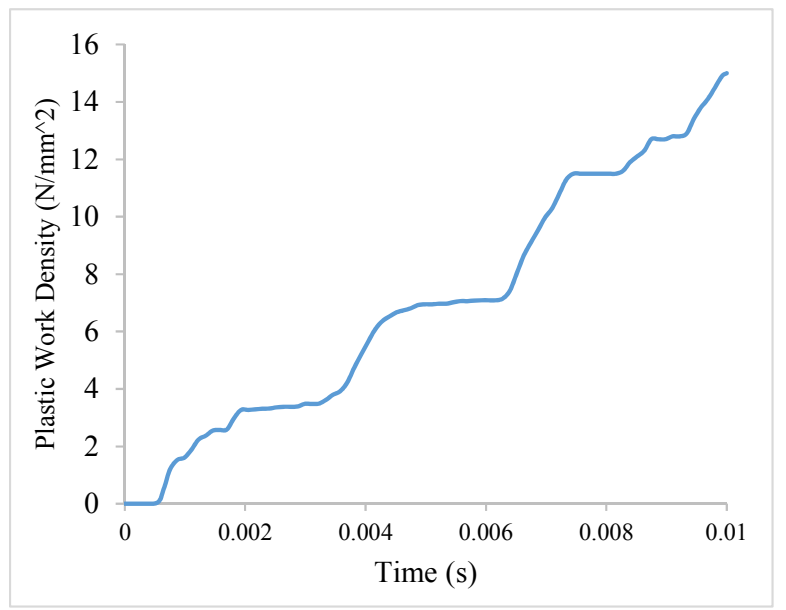

Figure 43: Plastic Work Density of Critical Solder Ball

Comparison of the Model Predictions for Viscoplastic Model and Linear Elastic Model of Solder Joints

The viscoplastic model depicts a very different response compared to the elastic model. This has been demonstrated by simulating the post-impact response of the printed circuit board assembly with a linear elastic model for the solder joints. A comparison of the stressstrain response of the solder joints represented with Anand Viscoplasticity has been compared with the response of the solder joints modeled with a linear elastic model. Figure 44 shows the comparison of the predicted board deflection from the finite element model with the viscoplastic model of the solder joints and the model with the linear elastic model of the solder joints. It can be seen that both the viscoplastic model and the linear model predict the same deformation behavior for the board assemblies. Figure 45 shows the comparison of the normal $\mathrm{x}$-strains along the longitudinal axis of the board assembly. Both the viscoplastic model and the linear elastic model exhibit similar transient board strain values. 
The strain values have been computed using the three methods mentioned for the viscoplastic model including the critical element, center element, and the volume averaged values of strain in the corner solder joint.

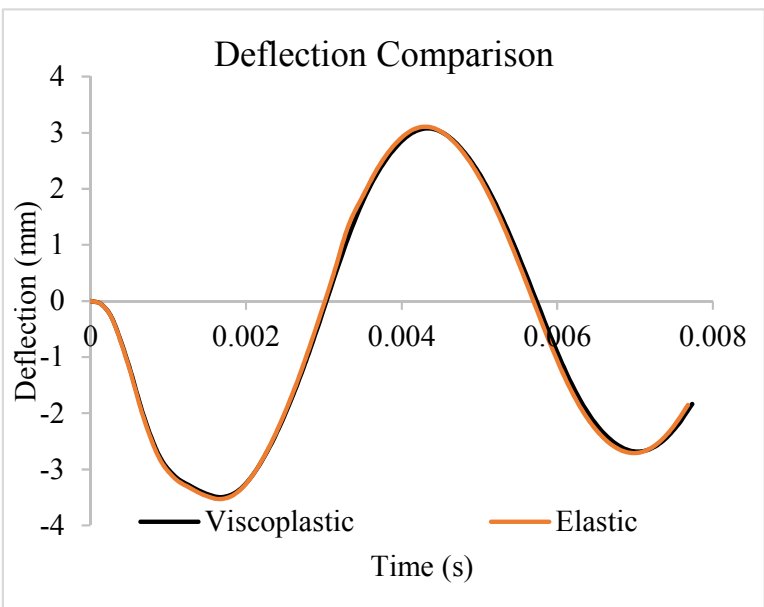

Figure 44: Deflection of PCB

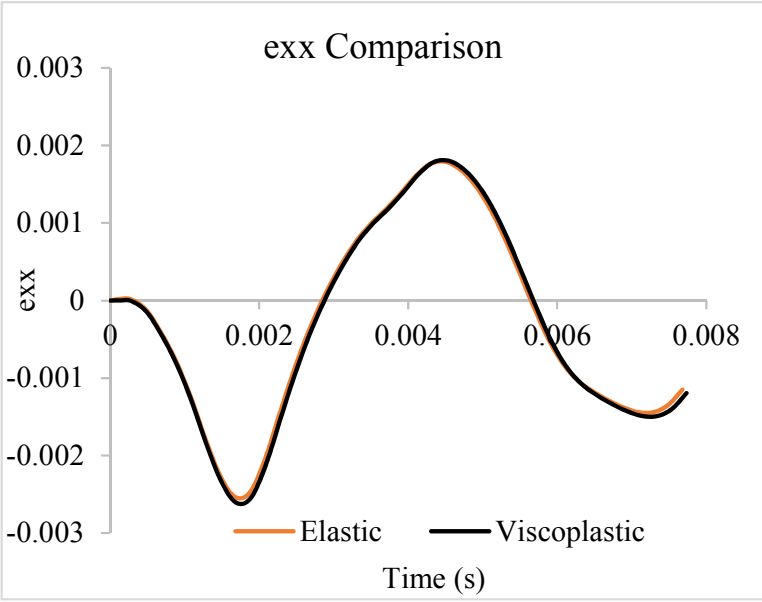

Figure 45: In-Plane Strain of PCB

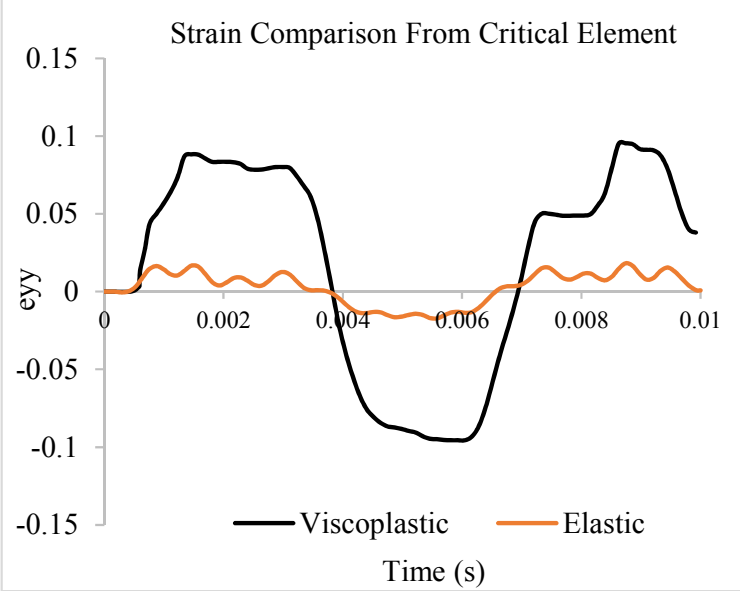

Figure 46: Strain Comparison from Critical SJ Element

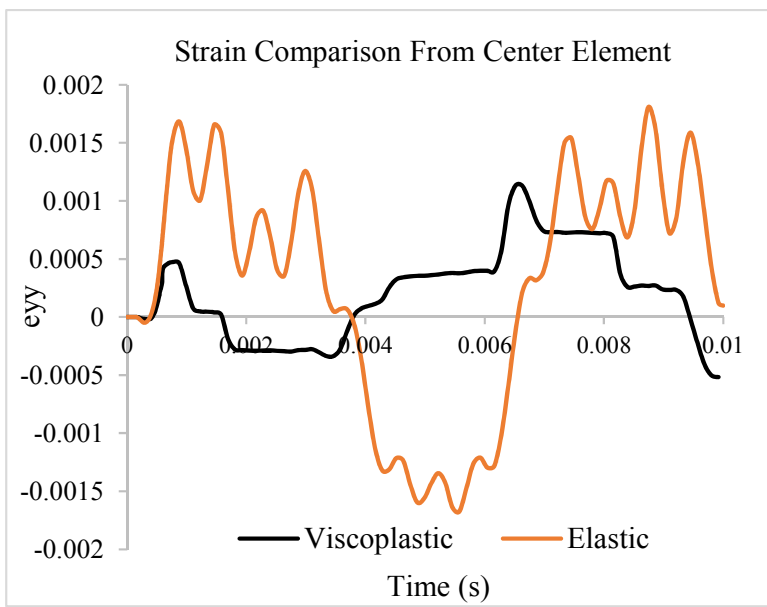

Figure 47: Strain Comparison from Center SJ Element

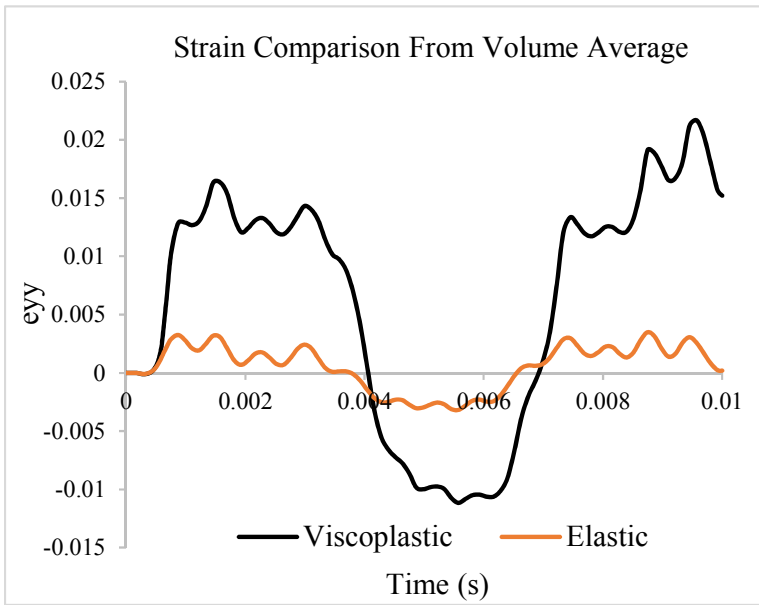

Figure 48: Strain Comparison from SJ Volume Average

The computed values for each of the three methods have been compared with the model predictions from the viscoplastic model in Figure 46 to Figure 48. The solder joint strains show significant differences between the viscoplastic model and the linear elastic model. The peak values of strain predicted by the linear elastic model are generally higher than the strain values predicted by the viscoplastic model.

\section{Summary and Conclusions}

In this paper, Uniaxial tensile tests for lead-free solders were carried out at 4 high strain rates $(\dot{\varepsilon}=10,35,50,75$ per sec) and 5 temperatures $\left(\mathrm{T}=25,50,75,100,125^{\circ} \mathrm{C}\right)$. High speed data acquiring system has been employed to capture the stress-strain curves. Procedures to determine the Anand constants from stress-strain curves at each particular condition were also established. Furthermore, a rate and temperature dependent constitutive model has been derived to describe the mechanical response of SAC105 and SAC305 at high strain rates. In addition, the accuracy of the extracted Anand constants has been evaluated by comparing the model prediction with experimental data. In all the cases, the predictive model 
correlated with mechanical response of SAC105 and SAC305 very well. The Anand Viscoplastic model has been used to predict the deformation and strain history of the printed circuit board and the solder joints under a $1500 \mathrm{~g}, 0.5 \mathrm{~ms}$ mechanical shock. The model predictions of board deformation and board strain have been predictions have been correlated with the measurements of board strain and board deformation from high-speed imaging in conjunction with digital image correlation. The model predictions show good correlation with experimental data. Furthermore, the model predictions from finite element model with viscoplastic constitutive material behavior has been compared with the model predictions from the finite element model with linear elastic constitutive behavior. There is a significant difference in the predicted solder joint strain values between the linear elastic model and the viscoplastic model predictions. Results indicate that is unreasonable to use linear elastic material properties to simulate the transient dynamic deformation and strain of solder joints under mechanical shock.

\section{Acknowledgments}

The research results presented in this paper have been supported by a grant from the National Science Foundation, NSF-FRS-1127913 and members of NSFCAVE3 Electronics Research Center.

\section{References}

1 Anand, L., "Constitutive Equations for the Rate Dependent Deformation of Metals at Elevated Temperatures," Journal of Engineering Materials and Technology, Vol. 104(1), pp. 12-17, 1982

2 Brown, S., Kim, K., and Anand, L., "An Internal Variable Constitutive Model for Hot Working of Metals," International Journal of Plasticity, Vol. 5(2), pp. 95-130, 1989.

3 Darveaux, R., K. Banerji, "Constitutive Relations for TinBased Solder Joints," IEEE Transactions on Components, Hybrids, and Manufacturing Technology, Vol. 15(6), pp. 1013-1023, 1992.

4 Sung, Y., Luo, G., Kerm, S. C., "A Viscoplastic Constitutive Model for 63Sn37Pb Eutectic Solders," Journal of Electronic Packaging, Vol. 124, pp. 91-96, 2002.

5 Chen, G., and Chen, X., "Constitutive and Damage Model for $63 \mathrm{Sn} 37 \mathrm{~Pb}$ Solder under Uniaxial and Torsional Cyclic Loading", International Journal of Solids and Structures, Vol. 43, pp. 3596-3612, 2006.

6 Wang, Q., Liang, L., Chen, F., and Weng, X., "Experimental Determination and Modification of Anand Model Constants for Pb-Free Material 95.5Sn4.0 Ag0.5Cu", EuroSIME 2007, London, UK, April, 2007.

${ }^{7}$ Motalab M, Cai Z, Suhling JC, Lall P. Determination of Anand constants for SAC solders using stress-strain or creep data. In: Proc. 13th IEEE Intersociety Conf. on
Thermal and Thermomechanical Phenomena in Electronic Systems (ITherm); 2012. p. 910-22.

8 Pang, H. L. J., Wang, Y. P., Shi, X. Q., and Wang, Z. P., "Sensitivity Study of Temperature and Strain Rate Dependent Properties on Solder Joint Fatigue Life," Proceedings of the 1998 Electronics Packaging Technology Conference (EPTC), pp.184-189, 1998.

9 Pei, M., and Qu, J., "Constitutive Modeling of LeadFree Solders," Proceedings of the International Symposium on Advanced Packaging Materials, pp. 4549, 2005.

10 Chuang, C. M., Liu, T. S., Chen, L. H., Effect of Aluminum Addition on Tensile Properties of Naturally Aged Sn-9Zn Eutectic Solder, Journal of Materials Science, Vol. 37(1), pp. 191-195, 2002.

${ }^{11}$ Coyle, R. J., Solan, P. P., Serafino, A. J., and Gahr, S. A., The Influence of Room Temperature Aging on Ball Shear Strength and Microstructure of Area Array Solder Balls, Proceedings of the 50th Electronic Components and Technology Conference, pp. 160169, 2000.

12 Darveaux, R., Shear Deformation of Lead Free Solder Joints, Proceedings of the $55^{\text {th }}$ Electronic Components and Technology Conference, pp. 882-893, 2005.

${ }^{13}$ Lee, S. W., Tsui, Y. K., Huang, X., and Yan, C. C., Effects of Room Temperature Storage Time on the Shear Strength of PBGA Solder Balls, Proceedings of the 2002 ASME International Mechanical Engineering Congress and Exposition, Paper IMECE2002-39514, pp. 1-4, 2002.

${ }^{14}$ Pang, J. H. L., Xiong, B. S., and Low, T. H., Low Cycle Fatigue Models for Lead-Free Solders, Thin Solid Films Vol. 462-463, pp. 408-412, 2004.

15 Tsui, Y. K. , Lee, S. W., and Huang, X., Experimental Investigation on the Degradation of BGA Solder Ball Shear Strength Due to Room Temperature Aging, Proceedings of the 4th International Symposium on Electronic Materials and Packaging, pp. 478-481, 2002.

${ }^{16}$ Zhang, Y., Cai, Z., Suhling, J.,C., Lall, P., Bozack, M., "Aging Effects in SAC Solder Joints," Proceedings of the SEM Annual Conference June 1-4, 2009 Albuquerque New Mexico USA, 2009.

17 Lall, P., Shantaram S., Panchagade D., PeridynamicModels Using Finite Elements for Shock and Vibration Reliability of Lead-free Electronics, Proceedings of ITHERM 2010,Las Vegas, NV, June 2-5, 2010.

18 Lall, P., Shantaram, S., Kulkarni, K., Limaye, G., Suhling, J.,"Constitutive Behavior of SAC Lead Free Alloys at High Strain Rates," Proceedings of the ASME 2011 Pacific Rim Technical Conference \& Exposition on Packaging and Integration of Electronic and Photonic Systems InterPACK201, July 6-8, 2011.

19 Lall, P., Choudhary, P., Gupte, S., Suhling, J., Health Monitoring for Damage Initiation and Progression during Mechanical Shock in Electronic Assemblies, IEEE Transactions on Components and Packaging 
Technologies, Vol. 31, No. 1, pp. 173-183, March 2008.

20 Lall, P., Shantaram, S., Angral, A., Kulkarni, M., Explicit Submodeling and Digital Image Correlation Based Life-Prediction of Leadfree Electronics under Shock-Impact, 59th Electronic Component and Technology Conference, pp 542-555, 2009.

${ }^{21}$ Madsen, K., Nielsen, H., B., Tingleff, O., Methods for Non-Linear Least Squares Problems, Technical University of Denmark, Lecture notes, available at http://www.imm.dtu.dk/courses/02611/nllsq.pdf, $\quad 2^{\text {nd }}$ Edition, pp. 1-30, 2004.

22 Lourakis, M., I., A., A brief Description of the Levenberg-Marquardt algorithm implemented by levmar, Foundation of Research \& Technology Hellas (Forth), Greece, pp. 1-6, Feb 11, 2005.

23 Nielsen, H., B, Damping Parameter in Marquardt's Method. Technical Report, IMM-REP-1999-05, Technical University of Denmark, Available at http://www.imm.dtu.dk/ hbn, pp. 1-16, 1999. 